\title{
The Social Network Application Post-Adoptive Use Model (SNAPUM): A Model Examining Social Capital and Other Critical Factors Affecting the Post-Adoptive Use of Facebook
}

\author{
Michael J. Magro \\ Shenandoah University, \\ Winchester, VA, USA
}

mmagro@su.edu

\author{
Sherry D. Ryan and \\ Victor R. Prybutok \\ University of North Texas, \\ Denton, TX, USA \\ sherry.ryan@unt.edu; \\ victor.prybutok@unt.edu
}

\begin{abstract}
Facebook is an informing social networking application that has experienced phenomenal worldwide user growth within a relatively short time and continues to grow at a rapid rate. This study examines the motivations for users to continue to use Facebook after adoption. Using a transdisciplinary approach, we draw on the technology acceptance research stream, post-adoption theories, and social capital theory to develop a model of the critical factors that affect the postadoptive use of Facebook. We argue that social capital is also poised to play a significant part in social networking informing environments for the foreseeable future. Other critical factors affecting post-adoptive use of Facebook include hedonic enjoyment, perceived usefulness, satisfaction, and attitude toward using.
\end{abstract}

Keywords: Facebook, informing environment, social networking applications, social capital, post-adoption.

\section{Introduction}

Social Networking Applications (SNAs) have experienced a surge in popularity in recent years. The term Social Networking Application is used in this paper instead of the more common Social Networking Site (SNS) because it is less platform specific (web sites are no longer the only means of social network content delivery) and is more inclusive of mobile devices and other means of accessing social networking computing offerings. Recent data suggests that $65 \%$ of U.S. teens use a SNA and up to $35 \%$ of Internet users age 55 and older make use of SNAs (Lenhart

Material published as part of this publication, either on-line or in print, is copyrighted by the Informing Science Institute. Permission to make digital or paper copy of part or all of these works for personal or classroom use is granted without fee provided that the copies are not made or distributed for profit or commercial advantage AND that copies 1) bear this notice in full and 2) give the full citation on the first page. It is permissible to abstract these works so long as credit is given. To copy in all other cases or to republish or to post on a server or to redistribute to lists requires specific permission and payment of a fee. Contact Publisher@InformingScience.org to request redistribution permission.
2009). In 2008, nine SNAs reported registered users of over 50 million each (Cardon, 2009). Four of those nine are estimated to have received over 100 million unique visitors, and two of the nine reported over 200 million unique visitors (Schonfeld, 2008). Among SNAs, Facebook has demonstrably outgrown its rivals growing an estimated 157 percent from 2008 to 2009. In 2009 Facebook had grown so large that it was es- 
timated to be the fourth largest Internet site in the world, trailing only Google, Microsoft, and Yahoo (Schonfeld, 2009), and as of March 2010, at least one measuring method showed Facebook to have surpassed Google in weekly U.S. traffic (Hardawar 2010). Since 2009, Facebook has embarked on a growth spurt that has more than quadrupled the amount of active users (more than 500 million active users as of July 21,2010), at times growing by over 700,000 users per day (Smith, 2009; Zuckerberg, 2010). Translated into over 100 languages, Facebook has demonstrated its ability to penetrate nearly one third of the national population in many developed nations, and these international growth rates are increasing (Smith, 2010). Thanks to the ubiquity of the Internet, Facebook may be modeling the most explosive growth curve ever experienced by an information technology. If there is a "killer app" for social networking, Facebook is it. Now is certainly the time to examine Facebook and its users during its highest growth phase and while it is still developing.

Social networking applications, such as Facebook, have become part of what we can call the informing environment, which can be understood as the collection of factors and influences that affect, enable, and limit the process of informing clients (Cohen, 2009). SNAs allow informers and clients to become interconnected by creating informal networks of friends to whom they communicate with and share information. According to Rambe and Ng'ambi (2009, p. 64), "an informer may focus on a subset of a network as a target to be informed," thus creating "layers of complexity and barriers to seeking and sharing information." Facebook's popularity notwithstanding, there is little research that has empirically examined the critical factors that contribute to the continued use of Facebook, or other SNAs, beyond initial adoption, and none to our knowledge that use an informing science transdisciplinary approach. Therefore, the research question for this present study is: What factors contribute to users continuing to use Facebook after adopting it?

Also noticeably absent are technology post-adoption studies that incorporate social capital as a motivating factor. Social capital is the benefits attained from the information shared and the relationships in which an individual participates. The core idea is that social networks have value. However, as Cohen (2009) discussed, there are issues in the informing environment that affect how clients attend, perceive, and act on information provided, thus influencing the social capital derived. The desire to obtain social capital can be a motivator for continued participation in the social networking informing environment. This study strives to fill the gap in transdisciplinary post-adoptive SNA research by examining the factors contributing to the post-adoptive continued use of Facebook and to advance the technological use theory stream by demonstrating the role that social capital can play in social networking technologies.

From a practitioner perspective, the answer to the question of what factors contribute to postadoptive Facebook use affects how businesses should approach leveraging SNAs to relate to their customers and how SNA design can be improved upon. Industry advisors assert that successful corporate entry into the online social networking community is not as simple as establishing a profile on a SNA and waiting for users to flock to the company's online presence (Warr 2008). Some companies have been successful utilizing SNAs, and some are still waiting for success. Addressing SNA usage in a satisfactory way will benefit both businesses and customers through knowledge that contributes to productive online communities that meet the needs of both entities. From an academic perspective, it is important for researchers to understand the specific aspects of SNAs that contribute most to continued use for a particular SNA because of the possibility that the same factors may contribute to continued use in other related or derived technologies.

We have adopted the philosophy of informing science as laid out by Cohen (2009) and conducted research on this phenomenon that is transdisciplinary in nature. There have been many studies of social networking applications done purely along disciplinary lines. Our research on social networking is steeped in theories from the disciplines of information systems, marketing, psychol- 
ogy, and communication. These disciplines have evolved and will continue to evolve, and with technology in the throes of constant change, it is imperative that social networking researchers avoid becoming isolated by discipline and the risk of developing weak theoretical models for want of input from other, relevant fields (Gill \& Cohen 2008).

This paper makes the following contributions to academic research. First, we review previous literature on the adoption and post-adoptive usage of technology, synthesizing it and theorizing on its application to a new context: the realm of social networking applications. Second, we develop and empirically test a theoretically grounded model that can be used and extended in future research on social networking, online communities, and social software. Social media is ubiquitous and has become an important part of users' daily lives. We argue that adoption and postadoption theories should be contextualized for this new environment which aids participatory information sharing and collaboration. Therefore, the derivation and empirical testing of such a model is timely and important. Third, we introduce a validated instrument for measurement of SNA usage factors to the field. We expand on the system usage construct used in Venkatesh, Brown, Maruping, and Bala (2008) by adding items designed to measure the breadth of usage in addition to frequency, duration, and intensity, thus clearly moving toward a richer conceptualization and measurement of usage.

\section{Theoretical Background}

The phrase post-adoptive use in this study refers to continued active use of the technology beyond the point where the technology was first adopted. Our goal in looking at post-adoptive use is to investigate the critical factors that explain why people continue to use a social networking site. Therefore, we use post-adoptive use as our research model's dependent variable. We note, however, that other approaches, such as examining changes in usage patterns from a baseline taken at adoption to a given (post-adoptive use) point in time, also have value and should be considered in future research.

In the remainder of the Theoretical Background section, we first discuss SNAs, themes of research in the SNA literature, and categories of SNA usage studies. Next, we discuss post-adoptive use. Third, we examine technology acceptance and post-adoptive model fit to SNAs. And fourth, we discuss the theoretical background of social capital.

\section{Social Networking Applications}

In this study, a SNA is defined as a computing application that supports and encourages online social networking. Users of SNAs participate in a kind of online community that simulates, after a fashion, the offline social interactions of individuals. SNAs are usually accessed through a web browser from a website, although they can also be accessed through mobile devices or other electronic means. SNAs typically share a common set of features which include:

a profile (representation and/or description) for each user, the means to build and manage a personal relational network (i.e., friends, family, acquaintances, etc.), and access to creative methods to communicate with members of their relational network and the online community. (Magro, Ryan, Sharp, \& Ryan, 2008, p. 1)

Academic literature on SNAs has begun to proliferate over the last few years but there is still a limited amount of knowledge on the phenomenon. An analysis of the available academic literature on SNAs for the last six years reveals a collection of five themes or areas of interest that are representative of the kinds of research being conducted on SNAs. The five themes are (1) general analysis of the SNA phenomenon; (2) privacy, trust, security, and ethics; (3) SNAs as artifacts; (4) SNA suitability as tools for a discipline, field of study, or division of industry; (5) SNA use and motivations for use. Key articles from each of these themes are listed in Table 1. 


\section{Table 1 Themes of Research in SNA Literature}

\begin{tabular}{|c|c|c|}
\hline Theme & Description & Examples \\
\hline $\begin{array}{l}\text { PRIVACYI } \\
\text { TRUST }\end{array}$ & Privacy, trust, security, or ethics & $\begin{array}{l}\text { Dwyer, Hiltz \& Passerini 2007; Fogel \& Nehmad 2009; Hinduja \& } \\
\text { Patchin 2008; Acquisti \& Gross } 2006 .\end{array}$ \\
\hline USE & Use and motivations for usage & $\begin{array}{c}\text { Bolar 2009; Bruque, Moyano \& Eisenberg 2008; Ellison, Steinfield \& } \\
\text { Lampe 2007; Hargittai 2008; Hu \& Kettinger 2008; Ross, Orr, Sisic, } \\
\text { Arseneault, Simmering, \& Orr 2009. }\end{array}$ \\
\hline TOOL & $\begin{array}{l}\text { Suitability as a tool for use by a } \\
\text { discipline, field of study, or divi- } \\
\text { sion of industry }\end{array}$ & $\begin{array}{l}\text { Bailey \& Zanders 2008; Baker-Eveleth, Eveleth \& Sarker 2005; } \\
\text { Connell 2009; Pasfield-Neofitou 2008; Lockyer \& Patterson } 2008 .\end{array}$ \\
\hline ARTIFACT & $\begin{array}{l}\text { Analysis of the design, improve- } \\
\text { ment, or assessment of SNAs as } \\
\text { artifacts }\end{array}$ & $\begin{array}{l}\text { Bouman, Hoogenboom, Jansen, Schoondorp, de Bruin \& Huizing } \\
\qquad 2007 .\end{array}$ \\
\hline GENERAL & $\begin{array}{l}\text { General Analysis of the SNA Phe- } \\
\text { nomenon (including history, } \\
\text { growth, classification, and general } \\
\text { user behavior) }\end{array}$ & $\begin{array}{l}\text { Boyd \& Ellison 2007; Brown, Broderick \& Lee 2007; Snyder, Car- } \\
\text { penter \& Slauson 2007; Thelwall 2008; Richter \& Koch 2008; Beer } \\
2008 .\end{array}$ \\
\hline
\end{tabular}

Additionally a sixth category exists and consists of a growing collection of individual case studies that look at a specific SNA or a specific user group for a purpose other than that listed above.

Of the six categories of SNA literature given above, our research question suggests that primary attention should be focused on SNA studies which examine use. To that end, we examined and categorized the literature on SNA usage into the following three groups: Motivations (reasons for use), Activities (what people use SNAs for), and Associations (factors associated with use or adoption which are not necessarily motivational). Examples of articles in each category are shown in Table 2. Of these categories, the literature that focuses on motivations for use is the most applicable to our research question.

\section{Table 2 Categories of Usage Studies in SNA Literature}

\begin{tabular}{|c|c|c|}
\hline Category & Description & Examples \\
\hline MOTIVATION & Reasons individuals use SNAs & $\begin{array}{l}\text { Agarwal \& Mital 2009; Arthur, Sherman, Appel \& Moore 2006; } \\
\text { Bolar 2009; Bumgarner 2007; DiMicco, Millen, Geyer, Dugan, } \\
\text { Brownholtz \& Muller 2008; Dwyer, Hiltz \& Widmeyer 2008*; } \\
\text { Lampe, Ellison \& Steinfield 2008; Pempek, Yermolayeva \& } \\
\text { Calvert 2009; Subrahmanyam, Reich, Waechter \& Espinoza } \\
\text { 2008* }\end{array}$ \\
\hline ACTIVITIES & $\begin{array}{l}\text { What people use SNAs } \\
\text { to do }\end{array}$ & $\begin{array}{l}\text { Dwyer, Hiltz \& Widmeyer 2008*; Ellison 2007; Ellison, Steinfield } \\
\text { \& Lampe 2006; Ellison, Steinfield \& Lampe 2007; Subrah- } \\
\text { manyam, Reich, Waechter \& Espinoza 2008* }\end{array}$ \\
\hline ASSOCIATIONS & $\begin{array}{l}\text { Factors associated with the use } \\
\text { or adoption of SNAs that don't fit } \\
\text { the above two categories }\end{array}$ & $\begin{array}{l}\text { Hargittai 2008; Pfeil, Arjan \& Zaphiris 2009; Ross, Orr, Sisic, } \\
\text { Arseneault, Simmering \& Orr } 2009\end{array}$ \\
\hline
\end{tabular}

\section{Post-Adoptive Use}

The second major category of our theoretical background section categorizes published studies on post-adoptive use of information technology. Our examination reveals two strong themes of research, user behavior and prediction/modeling, plus a third miscellaneous use category. There are many studies on post-adoptive user behavior (Hseih \& Zmud, 2006; Jasperson, Carter, \& Zmud, 
2005; etc.) where the focus is on categorizing and examining specific actions, behaviors, or perspectives that users develop after initial technology adoption. There are also studies that attempt to predict or model continued usage beyond adoption (Bhattacherjee, 2001; Saeed \& AbdinnourHelm, 2008; Wang, Lii, \& Fang, 2009). Additional studies examine specific aspects of postadoptive use (besides user behavior) that make them difficult to group together (Ahuja \& Thatcher, 2005; Al-Natour \& Benbasat, 2009; Mangalaraj, Mahapatra, \& Nerur, 2009). A summary of relevant post-adoptive literature is shown in Table 3. Of these categories, the collection of literature that focuses on continued usage beyond adoption is most applicable to our research question (What factors contribute to users continuing to use Facebook after adopting it?).

Table 3 Categories of Post-Adoption Usage Studies in IS Literature

\begin{tabular}{|c|c|c|}
\hline Category & Description & Examples \\
\hline USER BEHAVIOR & $\begin{array}{l}\text { Categorizing and examining specific } \\
\text { actions, behaviors, or perspectives } \\
\text { users develop after initial technology } \\
\text { adoption }\end{array}$ & $\begin{array}{l}\text { Hseih \& Zmud 2006; Jasperson et al. 2005; Kim, Mal- } \\
\text { hotra \& Narasimhan 2005; Karahanna, Straub \& Cher- } \\
\text { vany 1999; Bhattacherjee \& Premkumar 2004; Kim \& } \\
\text { Son } 2009 \text {; Wang et al. 2009*. }\end{array}$ \\
\hline $\begin{array}{r}\text { PREDICTION/ } \\
\text { MODELING }\end{array}$ & $\begin{array}{l}\text { Studies that attempt to predict or } \\
\text { model continued usage beyond adop- } \\
\text { tion }\end{array}$ & $\begin{array}{l}\text { Wang et al. 2009*; Bhattacherjee 2001; Saeed \& Ab- } \\
\text { dinnour-Helm 2008; Hu \& Kettinger } 2008\end{array}$ \\
\hline MISCELLANEOUS & $\begin{array}{l}\text { Studies examining specific aspects of } \\
\text { post-adoptive use (besides user be- } \\
\text { havior) that make them difficult to } \\
\text { group together }\end{array}$ & $\begin{array}{l}\text { Ahuja \& Thatcher 2005; Mangalaraj et al 2009; Al- } \\
\text { Natour \& Benbasat } 2009\end{array}$ \\
\hline
\end{tabular}

\section{Technology Acceptance and Post-Adoption Model Fit to SNA}

The technology acceptance stream of research informs our research question for several reasons. First, evidence supports the consistent stability of key pre-adoption constructs (perceived usefulness, behavioral intention, etc.) through continued system use after adoption (Davis \& Venkatesh, 2004; Taylor \& Strutton, 2010). Second, empirical studies suggest that past use is the primary predictor of future use (Davis \& Venkatesh, 2004; Kim et al., 2005; Venkatesh \& Davis, 2000). Third, post-adoption studies have used established Technology Acceptance Model (TAM) constructs successfully in their predictive models (Bhattacherjee, 2001; Wang et al. 2009).

There are two common themes with technology acceptance and Information Systems postadoption models. The first is the context of system use within organizational settings, such as the workplace. The second is the purpose of the system, which is almost always for utility or productivity.

Subsequent mainstream versions and extensions of TAM have continued to investigate phenomenon within the context of the organization. Few studies, in comparison, have looked at technology acceptance outside the organizational setting. A significant question therefore is whether a SNA, which is generally utilized outside an organizational context, is accepted in the same manner and for the same reasons as technology within an organizational setting? To begin answering that question, it is fruitful to examine SNAs for similarities to organizational computer information systems. First, SNAs are similar in that they can be considered information systems or "combinations of hardware, software, and telecommunications networks that people build and use to collect, create, and distribute useful data" (Jessup \& Valacich, 2006, p. 5). Second, in the area of functionality, SNAs enable communication with individuals or groups of individuals that are members of the SNA. In a similar manner, organizational information systems facilitate communication with members of the organization. 
However, SNAs also enable personal expression of identity and creative representation of the individual, while most organizational information systems do not. SNAs are often utilized by individuals for diversion or entertainment (Bumgarner, 2007) or when they have time to waste (Pempek et al., 2009), while organizational information systems typically are not. Additionally, SNA use is typically considered a social activity (Boyd, 2008; DiMicco \& Millen, 2007). While organizational information systems may have a social component, their primary purposes are characterized by utility or productivity (Hewitt, 1986; Huber, 1982).

A closer inspection of the origins of TAM reveals that the underlying theories (Theory of Reasoned Action, Theory of Planned Behavior) have no assumption of organizational context. Thus, there is also no compelling reason to believe that the efficacy of two main constructs, Perceived

Usefulness (PU) and Perceived Ease Of Use (PEOU) must only refer to usefulness that is specific to job performance or another organization-specific or employment-specific idea. It is reasonable that constructs from the TAM models should not be prohibited from measuring technology in a non-organizational setting simply because of their theoretical background and development. A difficulty may be that the majority of research using the TAM models has been on technology within organizations, and thus the instruments used to measure aspects of usage within a typical business setting need to be carefully scrutinized for organizational bias.

There are some examples of the use of various versions of the TAM model in non-organizational settings, even though the volume of non-organizational research is low compared to the volume of organizational research. A typical non-organizational study will start with a version of TAM and add one or more contextually-oriented antecedents to key variables and test the model for fit (e.g., Gefen, Karahanna, \& Straub, 2003; Hsu \& Lin, 2008; Kwon \& Chidambaram, 2000; Pikkarainen, Pikkarainen, Karjaluoto, \& Pahnila, 2004; Vijayasarathy, 2004). Various new antecedents are added to each model, usually in the form of salient beliefs theorized to affect the intention to use the application. The results of these studies of TAM in non-organizational settings are similar to the TAM studies done in organizational settings. There is usually a good model fit and a reasonable amount of variance explained. Thus, successful studies of TAM use in nonorganizational settings have been published and, because of this, there is not necessarily a barrier to fitting the various TAM models to the use of SNA technology. However, non-organizational studies must be careful not to assume that the purpose of the system is solely for utility or productivity.

\section{Social Capital}

The last category of our theoretical background section is social capital. Online communities and SNAs have a social aspect not found in many other types of information systems or online applications. One manifestation of the social facet of these applications is the presence of social capital. Social capital has been defined as "the sum of the actual and potential resources embedded within, available through, and derived from the network of relationships possessed by an individual or social unit" (Nahapiet \& Ghoshal, 1998, p. 243). Another way to understand social capital is as the benefits realized through the relationships in which the individual participates. Social capital has been found in online communities (Chiu, Hsu, \& Wang, 2006; Drentea \& MorenCross 2005; Ryan 2010), digitally enabled teams (Robert, Dennis, \& Ahuja, 2008), and in SNAs (Ellison, Steinfield, \& Lampe, 2007; Joinson, 2008; Pfeil, Arjan, \& Zaphiris, 2009; Steinfield, Ellison, \& Lampe, 2008). Social capital's close association with networked relationships makes it a likely candidate for inclusion as a motivational factor for continued SNA usage. On the individual level, social capital has been modeled as an antecedent of knowledge integration (Robert et al., 2008) and as an antecedent of affective feelings toward SNAs (Wu, Ryan, \& Windsor 2009). Certain aspects of social capital have also been postulated to be gained through using SNAs (Ellison et al., 2007). 
Social capital has been examined in a few SNA studies. Joinson (2008) found social capital manifested in maintained relationships on Facebook. Pfeil et al. (2009) found differences in social capital derived from SNAs between age groups. Donath \& Boyd (2004) found that SNA use supports the formation and maintenance of weak relational ties.

Past research studies have conceptualized social capital in different ways. Ellison et al. (2007) found three dimensions of social capital (bridging, bonding, and maintained) among users of Facebook. Bridging social capital is related to developing and sustaining weak relational ties among networked individuals. Weak ties are considered loose or weak connections between people who may share useful information or new ideas and perspectives, but generally not emotional support (Granovetter, 1982). Bonding social capital typically is represented by the kinds of relationships found between family and close friends, and characterized by emotional closeness (Ellison et al., 2007). Maintained social capital refers to the degree to which individuals are able to keep in touch with a social network using SNAs after disconnecting from it physically (Ellison et al., 2007). Nahapiet and Ghoshal (1998) conceptualized social capital in a different way with three dimensions consisting of structural, relational, and cognitive social capital (notably used in Robert et al., 2008). Structural social capital refers to the properties of the social linkages in place and the properties of the network of relations. Relational social capital describes the personal relationships between people in a social network. Cognitive social capital concerns the shared systems of meaning (i.e., representations, interpretations, languages, etc.) between people in a social network.

The dimensional definitions of bridging, bonding, and maintained social capital were selected for this study primarily because they had been successfully operationalized, tested, and validated on users of Facebook, and also because Facebook acts as a sort of funnel that constrains some of the broader ideas of social capital that might be seen in less specific contexts. For example, the structural dimension of Nahapiet and Ghoshal's (1998) definition concerns the properties of the social system and the configuration of network linkages between individuals. Facebook as a social networking aid provides a framework for that structure in the form of limitations, network structure, and outreach. Limitations are things like the inability to connect with someone who does not have a Facebook account or is not using it actively. The network structure restricts the kinds of communication and the level of communication Facebook allows. Also outreach, or the ability to add new individuals to your network, is constrained by Facebook's limited communication channels outside of itself (e-mail or friend-of-a-friend if they happen to be on Facebook). Likewise, the cognitive dimension represents "shared representations, interpretations, and systems of meaning among parties" (Nahapiet \& Ghoshal 1998), but all users of Facebook should be assumed to have a certain level of cognitive social capital due to all using the same interface, features, and terminology which is forced upon them by the specific medium.

The elastic nature of social capital makes it a complex construct. In the case of SNA usage it is suggested that social capital will likely be manifest as both a cause and an effect. For initial adoption and use of SNA technology, actual social capital will likely have little influence due to the lack of time to develop it. Indeed, anticipated social capital, if there is such a thing, could possibly be a motivating factor. However, after continued use, we argue that aspects of social capital will be experienced as a benefit by the user, which will serve as additional motivation for continued use.

\section{Research Model and Hypotheses Development}

A set of motivational factors was derived from the literature on SNA and technology adoption research. The literature on motivations for using SNAs discusses many factors including hedonic pleasure, social connection, utility, (Bumgarner, 2007), relationship maintenance, new relationship discovery (Dwyer et al., 2008), to strengthen weak ties in existing relationships (Lampe, 
Ellison, \& Steinfield, 2008), and engaging in interesting activities (Pempek et al., 2009). To cover these factors, we used the following motivating constructs: social capital (SC), hedonic enjoyment (HE), and perceived usefulness (PU).

To model post-adoptive behavior, we drew on Bhattacherjee's (2001) Post-Acceptance Model of IS Continuance. Bhattacherjee's model was derived from the Expectation-Confirmation Theory (ECT) often used in consumer behavior research. His model uses satisfaction and perceived usefulness as the antecedents to continuance intention (CI). Our research model incorporates the post-adoptive measure of continuance intention, satisfaction, and also includes perceived usefulness from Bhattacherjee's model as a motivational factor, as stated above.

Finally, an extended measure of system post-adoption use is established as the dependent variable for the model. The proposed research model, which we entitle the Social Networking Application Post-adoptive Use Model (SNAPUM), is shown in Figure 1. All the constructs appearing in the model are discussed below.

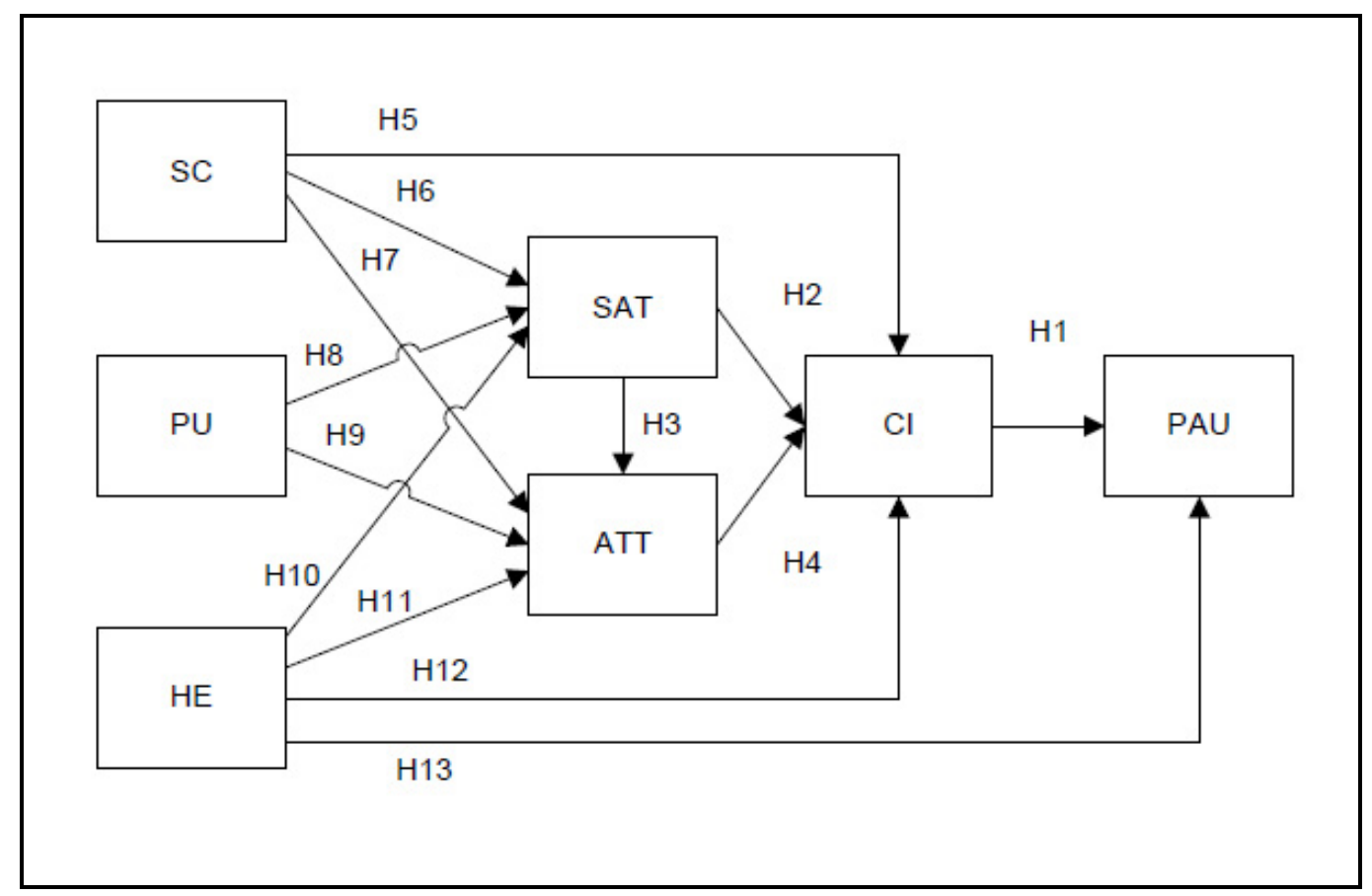

Figure 1: SNAPUM Model with Hypotheses

Post-Adoptive Use is especially important to the Information Systems community because the ultimate success of an information system depends on its "continued use rather than first time use" (Bhattacherjee (2001, p. 352). System usage, in general, has been a part of the user adoption literature since the earliest models. Recently a call has been made to refine what is meant by system usage as well as what is actually being measured. Traditional Information Systems studies have measured system use as an amount or frequency, which is a simplistic view of usage and one that has important shortcomings (Benbasat \& Barki, 2007). System usage can be seen as a much more complex factor, and is able to be measured more precisely if the researchers desire (Burton-Jones \& Straub, 2006; Jasperson et al., 2005).

The early TAMg studies measured self-reported use on a limited scale of frequency (Davis, 1986; Davis, Bagozzi, \& Warshaw, 1989, Venkatesh \& Davis, 2000). The United Theory of Acceptance and Use of Technology (UTAUT) measured actual system use using undisclosed system metrics (but there is no mention of time, frequency, intensity, features, etc.) (Venkatesh, Morris, Davis, \& Davis, 2003). The follow up to UTAUT measured system usage through self-reported 
measures of intensity, frequency, and duration (Venkatesh et al., 2008). It can be seen that the various TAM models have, over time, developed a more complex measure of system usage, albeit very slowly.

Burton-Jones \& Straub (2006) delivered a reconceptualization of the system usage construct, identifying six types of richness for system usage measures. The first type, characterized as very lean, measures only use or non-use of the system. The second type, characterized as lean, measures duration and/or extent of use. The TAM and UTAUT models fall into this second category. The third type is characterized as somewhat rich and measures the breadth of use by the number of features used. The fourth type, characterized as rich, measures the extent to which the user employs the system, or intensity of use. The fifth type, also characterized as rich, measures the extent to which the system is used to carry out tasks, or the variety of use. The sixth type, characterized as very rich, measures the extent to which the user employs the system to carry out the task. Venkatesh et al. (2008) employed a usage measure that covered three aspects of system use: frequency, duration, and intensity. This can be seen to encompass parts of types 1, 2, and 4 and, therefore, can be classified between somewhat rich and rich, according to the Burton-Jones and Straub richness of measures scale.

The importance of the system use construct cannot be overstated. It has been the dependent variable for a steady stream of technology adoption studies for many years. The technology adoption studies have generally suffered from an underdeveloped system usage construct (Benbasat \& Barki, 2007, Straub \& Burton-Jones, 2007). In this study we will expand on the system usage construct used in Venkatesh et al. (2008) by adding items designed to measure the breadth of usage in addition to frequency, duration, and intensity, thus clearly moving the measurement of usage toward the rich category.

Continuance intention is derived from Bhattacherjee's (2001) post-adoptive model of IS continuance. Continuance intention in this study is the measure of a user's intention to continue using Facebook. We argue that intention should be positively associated with the measure of postadoptive system use in the same way behavioral intention to use was found to be positively associated with pre-adoptive system use in many TAM studies. Thus:

H1: Continuance intention will have a positive effect on post-adoptive use.

The satisfaction construct also comes from the Expectation-Confirmation model established by Bhattacherjee for post-adoptive Information Systems use. User satisfaction has been theorized and validated as an important predictor of use intention (Bhattacherjee, 2001; Oliver, 1980, 1981). In Bhattacherjee's model, perceived usefulness was found to influence user satisfaction, which in turn influenced the user's intention to continue to use the information system. We posit here that user satisfaction will play a similar role in post-adoptive SNA use and that satisfied users will be more favorably disposed to continue to use Facebook. Additionally, satisfaction is expected to influence attitude toward using. Attitude will be discussed in more detail shortly, but both attitude and satisfaction are measures of emotional disposition. Attitude is considered to reflect a longer-term outlook than satisfaction, which tends to be based more on recent experiences. Therefore, we posit that short-term satisfaction will have an influence on the longer-term attitude. This relationship has been validated in other studies (Bearden \& Teel, 1983; Oliver, 1980; Sivadas \& Baker-Prewitt, 2000; Taylor \& Hunter, 2003; etc.).

$\mathrm{H} 2$ : User satisfaction will have a positive effect on the user's continuance intention.

H3: User satisfaction will have a positive effect on the user's attitude towards using. 
Attitude is a relatively enduring affect that transcends experiences alone and reflects the emotional disposition of the user toward the technology (Hunt, 1977; Oliver, 1980, 1981). The attitude construct is a valuable measure that potentially accounts for salient beliefs other than those specifically measured in most acceptance instruments. Attitude has been theorized and validated in TAM-based studies as a significant predictor of intention to use (Davis et al., 1989; Karahanna, Straub, \& Chervany, 1999; Taylor \& Todd, 1995; etc.). In this study, it is positioned as an antecedent to continuance intention with three antecedents of its own (perceived usefulness, social capital, and social influence).

H4: Attitude toward using will have a positive effect on the user's continuance intention.

In this study social capital is hypothesized to affect continuance intention and post-adoptive use. The relationship between social capital and these core constructs is suggested by the social nature of Facebook. The reward of social capital is expected to be a driving influence for people to continue to use Facebook. Therefore the user's level of satisfaction will be increased by the amount of social capital experienced. The attitude toward using will be more positive according to the amount of social capital gained. The intention to continue using will be related to the expectation of a steady or increasing level of social capital experienced by the user. Therefore:

H5: Social capital will have a positive effect on the user's continuance intention. H6: Social capital will have a positive effect on the user's satisfaction.

H7: Social capital will have a positive effect on the user's attitude toward using.

Perceived usefulness has been present in technology acceptance literature since the original TAM model and has persisted through many technology adoption studies of various and diverse technologies. In Bhattacherjee's Expectation-Confirmation model, it is supported as an antecedent to user satisfaction and it is expected to act the same in this study. Additionally, the early TAM models containing attitude toward using found support for perceived usefulness influencing the attitude construct, and that is also hypothesized here.

H8: Perceived usefulness will have a positive effect on user satisfaction.

H9: Perceived usefulness will have a positive effect on the user's attitude toward using.

Many studies of SNA usage point to the concept of entertainment or enjoyment as a benefit of using SNAs, and conversely, a motivational factor for continued use (Agarwal \& Mital, 2009; Bolar, 2009; Bumgarner, 2007; DiMicco et al., 2008; Pempek et al., 2009; Subrahmanyam, Reich, Waechter, \& Espinoza, 2008). This aspect of SNAs makes them at least in part a hedonic information system. Hedonic information systems are designed to provide enjoyment to the user, while utilitarian systems (of which organizational information systems are a part) are designed to provide instrumental value to the user (van der Heijden, 2004). The construct perceived enjoyment in van der Heijden's (2004) study was found to have more predictive power than perceived usefulness, which typically has a high predictive power. Perceived enjoyment (or hedonic enjoyment as it is called in this study) appears to be highly applicable to SNAs, and is expected to influence the user's satisfaction with using the system. Therefore:

H10: Hedonic enjoyment will have a positive effect on the user's satisfaction. H11: Hedonic enjoyment will have a positive effect on the user's attitude toward using.

H12: Hedonic enjoyment will have a positive effect on user continuance intention. 
H13: Hedonic enjoyment will have a positive effect on the user's post-adoptive use.

There are several constructs not included in this model that are worth noting. Facilitating conditions is a measure used in the UTAUT model and was in turn derived from a combination of constructs (perceived behavioral control, facilitating conditions, and compatibility) from several authors (Venkatesh et al., 2003, p. 453). Facilitating conditions can be seen as the degree to which an individual believes that conditions are in place to facilitate their ready, easy, and effective use of the system. The broad concept of facilitating conditions may be relevant for social networking systems in some contexts, but overall it is considered unlikely that there are any substantial limitations on the use of social networking applications for post-adoptive users. For example, as previously mentioned, SNAs are generally used outside of an organizational structure. Therefore the typical user has no need for an organizational infrastructure to support their use of their SNA. Also, the concept of compatibility with other systems used for work is not applicable to social networking systems which are not work systems.

Social influence was present in UTAUT, defined as "the degree to which an individual perceives that important others believe he or she should use the new system" (Venkatesh et al., 2003). In UTAUT it represented a combination of three factors: subjective norm, image, and social factors. However, the social factors concept in UTAUT is highly organizational and job-related, making it largely irrelevant to SNA use. The other two dimensions, subjective norm and image, are likely to overlap the social capital measure in some manner. In pilot studies, we found that subjective norm measured as a weak, negative relationship, suggesting that peer pressure to use SNAs is not as strong as what might be thought. Therefore, social influence by itself outside of social capital is not considered a strong motivator for SNA use.

Perceived ease of use has been present in technology acceptance research since the original TAM model. It has proved to be a very useful measure of capturing relevant beliefs in the context of information technology usage (Benbasat \& Barki, 2007). Perceived ease of use has been wellestablished as an antecedent to behavioral intention to use in pre-adoption studies. However, some studies have found that perceived ease of use seems to diminish and become non-significant as users become more experienced with the system (Davis et al., 1989; Karahanna et al., 1999). It is reasonable to suspect that most ease of use issues will have been largely overcome by those who have adopted the system. Additionally, user comments from focus groups conducted on SNA usage have indicated SNAs have a very fast adoption rate and are considered easy to use. Therefore, we did not include perceived ease of use in our model as a motivational factor for post-adoptive use of SNAs.

There were a number of moderating factors introduced by the UTAUT model which were shown to influence various relationships in that model. Age, gender, voluntariness of use, and experience were hypothesized to affect the influence of several variables on others in the UTAUT model, including performance expectancy (perceived usefulness with a job-related context) on behavioral intention to use, effort expectancy (derived from perceived ease of use) on behavioral intention to use, and social influence on behavioral intention to use. Gender and age hypotheses were supported primarily by studies on working women and worker age (Venkatesh et al., 2003). However, outside of a job-related context, there is a lack of evidence at this time that gender will significantly affect SNA post-adoptive usage. Therefore gender will not be included as a moderator in the theoretical model. Experience is also not anticipated to be a significant modifier because of the context of post-adoption which entails that all users will have significant experience using the system due to their system use taking place beyond initial acceptance. Voluntariness of use is not applicable in a non-mandated use environment outside of the workforce. While there certainly exist those who must use Facebook as a part of their job or educational efforts, these 
instances are likely to be few and far between. In the UTAUT model, age was shown to be a modifier of several construct relationships through its influence on behavioral intention to use. While these moderating relationships may hold for SNA usage, the expected sample population of students in our study is not expected to have enough variance in age ranges to make it a significant measure. Therefore, age will not be included as a moderator.

\section{Research Methods}

We employed a structured approach consisting of the following steps: 1) pilot surveys with user feedback, 2) survey data collection, 3) measurement validation, and 4) hypothesis testing.

\section{Pilot Surveys}

The survey instrument used was developed through a series of steps. First, a pilot survey was developed incorporating constructs and items from previously established instruments as well as modified constructs and items from established instruments and literature. The pilot survey was examined for content validity by two other researchers who have published research on the subjects of social networking applications and system usage. The pilot survey was itself tested by administration of a "pre-pilot" among 62 undergraduate students of a business course at a large Midwestern university. The pre-pilot respondents took the survey, commented on its clarity, and checked it for errors. Changes were made to the pilot survey based on comments and suggestions from the pre-pilot sample population.

The pilot study was then administered to a selection of four classes in the College of Business of a large Midwestern university in the United States with the permission of the instructors of the classes. Out of a total of 232 possible respondents, 118 participated in the pilot for a response rate of $51 \%$. The sample was too small to use with structural equation modeling, but the constructs were examined using exploratory factor analysis for validity and Cronbach's alpha for reliability.

\section{Sample Survey}

The sample surveyed consisted of undergraduate and Master's students taking courses in the College of Business at a large Midwestern university. Students in particular have been shown to be heavy Facebook users as evidenced by their inclusion as sample populations in many studies (Hewitt \& Forte, 2006; Lampe, Ellison, \& Steinfield, 2006; Pempek et al., 2009; etc.). Facebook demographics reported for 2009 indicate that of the users that chose to specify, the majority were currently enrolled in college, and that over $40 \%$ of Facebook users were in the 18-24 age range (Corbett, 2009).

\section{Measures}

The items for each of the measures discussed below are listed in the Appendix.

Post-adoptive use in this study was initially adapted from Venkatesh et al.'s version of system usage, which measures three aspects of usage (with a single item each), duration, frequency, and intensity of use, which are cited as the three most common conceptualizations of system use (Venkatesh et al. 2008). The intensity of use measure was discovered to be confusing when applied to SNAs in a pilot study and thought to be problematically vague when checked for content validity by other researchers in the context of SNA use. The concept of intensity was operationalized for system usage in the Venkatesh et al. (2008) model and said to be synonymous with extent of use. In this study, intensity and extent of use are considered to be different measures of two separate usage aspects. The first aspect of usage intensity is operationalized as the concept of involvement or immersion in the use of the SNA, which is a type of cognitive absorption. This 
usage measure is supported as an aspect of SNA usage by literature (Horowitz, 2009; Warr, 2008). The second intensity usage aspect, extent, represents the concept of breadth of use, or how much of the system is actually used, and is operationalized as a measurement of the degree of feature-usage by the individual, as suggested for richer usage measures by Burton-Jones and Straub (2006). Seven measurement items are used: one each for duration and extent, two for frequency, and three for involvement. This construct constitutes the first instance of this combination of system use measures that we are aware of.

Continuance intention is defined as the degree of an individual's intent or plan to continue to use the application after initial adoption or acceptance. This measure was taken from Bhattacherjee's (2001) ECM model. Three total items were used to measure this construct.

The satisfaction construct comes from Bhattacherjee's (2001) post-adoptive IS use model. It asks the users to disclose their level of satisfaction/dissatisfaction, pleasure/displeasure, contentment/frustration, and delight/non-delight with their overall experience using their current SNA. Four total items were used to measure this construct.

Attitude toward using was measured in UTAUT but theorized not to be a predictor of intention to use within the context of that study. The items used to measure attitude in UTAUT were a combination of attitude, affect, and intrinsic motivation. It included some items similar to those used to measure hedonic enjoyment. The attitude construct used in this study comes from Malhotra and Galetta's (1999) TAM extension, with an additional item from Nysveen, Pedersen, and Thorbjornsen (2005). Five total items were used to measure this construct.

The social capital construct does not have a single established instrument. Many different measurement instruments have been used in recent studies, including but not limited to the following: Chiu et al., 2006; Drentea \& Moren-Cross 2005; Ellison et al. 2007; Inkpen and Tsang 2005; Kuo, Lai, \& Wang 2008; Lee \& Sukoco 2007; Luk, Yau, Sin, Tse, Chow, \& Lee 2008; Robert et al. 2008; Wah, Menkhoff, Loh, \& Evers 2007. For this study, the social capital measurement instrument was adapted from Ellison et al. (2007), which draws on Putnam's (2000) distinction between bridging and bonding and was shown to be an effective social capital measure for Facebook. The social capital construct as operationalized in this study consists of three dimensions: bridging, bonding, and maintained. The measure for maintained social capital asks questions about the respondent's high school friends to determine if those relationships have been able to be maintained after starting college. Higher education signifies, in many cases, a break in the relationship both in terms of status and in physical location. The bridging dimension contains 4 measurement items, the bonding dimension contains 4 measurement items, and the maintained dimension contains 5 measurement items.

Perceived usefulness is a construct present in virtually all the TAM-related models. It is defined construct in related models. Three items were taken from the TAM model and two new items were created to match Facebook use according to the definition of the construct. Five total items were used to measure this construct.

The measures for hedonic enjoyment were derived from two constructs used in prior studies, one called hedonic enjoyment (Waterman, Schwartz, \& Conti 2008) and the other perceived enjoyment (van der Heijden, 2004). One item was taken from Waterman et al. (2008), one item was taken from van der Heijden (2004), and two new items were created to match Facebook use according to the definition of the construct. Four total items were used to measure this construct.

To differentiate between pre-adoptive system usage and post-adoptive use, an effort was made to determine the length of continuous system usage required to transform a user from someone learning or trying out the product to an accomplished dedicated adopter. During the focus groups conducted prior to the main study, each participant was asked for their opinion regarding how 
long it took from their first use of Facebook for them to adopt it as an application they regularly used and how long it took from their first use of Facebook before they would have called themselves a Facebook user. The answers to both questions were largely identical and averaged from 1 to 2 weeks, with no respondent naming a time longer than 3 weeks. Therefore, the period from initial use to "adoption" appears to be no longer than 21 days. However, in this study, to ensure that respondents were truly in the post-adoptive stage, we took a very conservative approach and required that respondents had at least 60 days of regular Facebook use and that they use Facebook currently and regularly.

\section{Characteristics of the Survey Sample}

Overall, a total of 2000 students had the potential to be surveyed (based on class enrollment at the time of survey administration), and 1430 total responses were recorded (this total does not include blank responses or extremely incomplete responses likely to be disconnections from the electronic survey tool). The response total yields an aggregate response rate of $71.5 \%$, which is favorable. A response was kept only if it met the following criteria: (1) the user expressed that $\mathrm{s} /$ he had used a social networking application before, and that $\mathrm{s} /$ he was currently using a social networking application now; (2) the user supplied the name of the SNA s/he used most often as Facebook (users were instructed in the survey to answer questions in the context of the use of the SNA they used most often); (3) the user indicated s/he had more than two months of experience using their SNA. The total number of responses left after applying these criteria totaled 964.

Non-response bias has been addressed in past survey research by comparing early responses with late responses to determine if there are any differences between the two groups of respondents (Karahanna et al., 1999; Ryan, Harrison, \& Schkade, 2002). This method was employed using the results from the electronically administered surveys that record the date and time of responses. Respondents were split into two groups, where the first group consisted of responses received during the first two weeks after the announcement that the electronic survey was available, and where the second group consisted of responses received during the last week the survey was active before it closed. T-tests were conducted to examine the differences between the two groups in regards to their responses to independent and dependent variables. The results showed no significant differences between the groups, suggesting that non-response bias is not a significant influence in this study.

\section{Measurement Validation}

The variables used in this study were measured using several items each in a survey instrument. The ability of the instrument to properly measure these variables is typically evaluated by assessing the construct validity and reliability of each variable (Hair, Black, Babin, Anderson, \& Tatham, 2006; Kerlinger \& Lee, 2000). A common indicator of construct validity is its unidimensionality, which can be evaluated using exploratory factor analysis (EFA) (Beatty, Shim, \&Jones, 2001). Cronbach's alpha is a common method for assessing reliability (Kerlinger \& Lee, 2000).

The dimensionality of the items was examined using principal component factor analysis with a Varimax rotation. The resulting factors extracted were examined and analyzed according to the following two criteria. First, items having factor loadings of more than 0.5 on the construct on which they are expected to load can be considered to be a satisfactory measure of that construct. Second, items having factor loadings of more than 0.45 on constructs other than the one they are expected to load on are considered cross-loading items and are not dependable measures of the expected construct (Hair et al. 2006). Separate factor analyses were conducted for the independent, mediating, and dependent variable groups respectively rather than a single factor analysis for all variables at once, which would result in a correlation matrix of over 1900 and be of little value 
(Gefen \& Straub, 2000; Jones \& Beatty, 2001). All EFA factor loadings were .726 or higher. The results are displayed in Tables 4 through 6.

Table 4 EFA on Independent Variables

\begin{tabular}{|c|c|c|c|c|c|}
\hline \multirow[b]{2}{*}{ Items } & \multicolumn{5}{|c|}{ Components } \\
\hline & 1 & 2 & 3 & 4 & 5 \\
\hline SCM1 & .740 & .074 & .271 & .144 & .290 \\
\hline SCM2 & .797 & .160 & .129 & .211 & .209 \\
\hline SCM3 & .789 & .160 & .141 & .216 & .187 \\
\hline SCM4 & .795 & .134 & .243 & .165 & .099 \\
\hline SCM5 & .816 & .094 & .151 & .168 & .171 \\
\hline PU3 & .148 & .871 & .154 & .138 & .176 \\
\hline PU4 & .146 & .891 & .161 & .159 & .122 \\
\hline PU5 & .128 & .806 & .194 & .092 & .111 \\
\hline HE1 & .258 & .202 & .820 & .155 & .180 \\
\hline HE2 & .213 & .211 & .842 & .171 & .212 \\
\hline HE3 & .254 & .182 & .800 & .162 & .178 \\
\hline SCBO1 & .222 & .097 & .187 & .849 & .218 \\
\hline SCBO2 & .240 & .137 & .164 & .872 & .177 \\
\hline SCBO4 & .253 & .210 & .126 & .745 & .230 \\
\hline SCBR1 & .240 & .129 & .162 & .220 & .846 \\
\hline SCBR2 & .275 & .149 & .227 & .224 & .817 \\
\hline SCBR3 & .266 & .232 & .222 & .230 & .734 \\
\hline Mean & 5.327 & 4.631 & 5.277 & 4.989 & 5.041 \\
\hline Eigen. & 3.715 & 2.57 & 2.504 & 2.487 & 2.422 \\
\hline $\begin{array}{l}\text { Var. } \\
\text { Expl'd. }\end{array}$ & $21.85 \%$ & $15.12 \%$ & $14.73 \%$ & $14.63 \%$ & $14.25 \%$ \\
\hline Alpha & 0.912 & 0.888 & 0.901 & 0.894 & 0.896 \\
\hline $\begin{array}{l}\text { SCM } \\
\text { tained }\end{array}$ & I Capital & & SCBO: & cial Capita & Bonding \\
\hline PU: & ved Usefu & & SCBR: & cial Capita & Bridging \\
\hline HE: & c Enjoym & & & & \\
\hline
\end{tabular}


Table $5 \quad$ EFA on Mediating Variables

\begin{tabular}{lrrr}
\hline & \multicolumn{3}{c}{ Components } \\
Items & 1 & 2 & 3 \\
\hline ATT1 & .792 & .173 & .127 \\
ATT2 & .795 & .122 & .197 \\
ATT3 & .828 & .191 & .142 \\
ATT4 & .825 & .233 & .198 \\
SAT2 & .239 & .825 & .352 \\
SAT3 & .214 & .869 & .275 \\
SAT4 & .218 & .880 & .204 \\
Cl1 & .181 & .270 & .868 \\
Cl2 & .171 & .244 & .861 \\
Cl4 & .236 & .250 & .826 \\
\hline Mean & 5.028 & 5.378 & 5.476 \\
Eigen. & 2.894 & 2.540 & 2.533 \\
Var. & & & \\
Expl'd. & $28.95 \%$ & $25.40 \%$ & $25.33 \%$ \\
Alpha & 0.867 & 0.920 & 0.894 \\
\hline ATT: Attitude & & Cl: Continuance Intention \\
SAT: Satisfaction & & &
\end{tabular}

Table 6 EFA on Dependent Variable

\begin{tabular}{lc}
\hline Items & Component \\
\hline PAUD &. $\mathbf{7 7 8}$ \\
PAUFR1 & .738 \\
PAUFR2 & .851 \\
PAUI1 & .906 \\
PAUI2 & .902 \\
PAUI3 & .901 \\
PAUE & .726 \\
\hline Mean & 4.008 \\
Eigen. & 4.849 \\
Var. & $69.27 \%$ \\
Expl'd. & 0.924 \\
Alpha & \\
\hline
\end{tabular}

PAUI: Post-Adoptive Use (Intensity)

PAUFR: Post-Adoptive Use (Frequency)

PAUD: Post-Adoptive Use (Duration)

PAUE: Post-Adoptive Use (Extent)

\section{Test of the Measurement Models}

The structural equation modeling tool LISREL was used to create measurement models for the constructs and a model to test the proposed hypotheses. As a first step, the multi-dimensional variables for social capital was reduced to a single measurement item for each second-order factor by averaging the values for each item into a composite score (Lee \& Xia, 2010; Yi \& Davis, 2003). Thus, the three remaining items that measured bonding were averaged to form one value to serve as one of three measurements. The same was done with bridging and maintained, so that social capital is now measured by three items and acts as a first-order construct. The same process was performed for the two multi-dimensional aspects of the dependent variable, postadoptive use.

Measurement models were created for the exogenous and endogenous variables. Each measurement model describes the relationship of observed variables to their corresponding latent variables. This is accomplished by assessing the reliability and validity of the measures (Komiak \& Benbasat, 2006; Tenenhaus, Vinzi, Chatelin, \& Lauro, 2005). Convergent validity can be assessed by examining the composite reliability and the average variance extracted (AVE) of the constructs (Barclay et al., 1995; Hu, Lin, Whinston, \& Zhang, 2004; Komiak \& Benbasat, 2006) in the models. The AVE represents the amount of variance explained by the indicators of a construct relative to the amount of variance captured as a result of the measurement error (Chin, 1998; Hu, Lin, Whinston, \& Zhang, 2004; Komiak \& Benbasat 2006). The results of the item loadings and the AVE values for each construct are shown in Tables 7 and Table 8. Recommended AVE values should be greater than 0.5 for an adequate measurement model. All AVE scores show as greater than 0.6 which is above the recommended value. 
Magro, Ryan, \& Prybutok

Table $7 \quad$ CFA for All $\mathbf{X}$ Model

\begin{tabular}{rrrrr}
\hline & $\begin{array}{c}\text { Completely Stan- } \\
\text { dardized Loading }\end{array}$ & t-statistics & $\begin{array}{l}\text { Average } \\
\text { Variance } \\
\text { Extracted }\end{array}$ & $\begin{array}{l}\text { Composite } \\
\text { Reliability }\end{array}$ \\
\hline PU & & & $\mathbf{0 . 7 4 1}$ & $\mathbf{0 . 8 9 4}$ \\
P3 & 0.90 & 34.66 & & \\
P4 & 0.94 & 36.80 & & \\
P5 & 0.73 & 25.72 & & $\mathbf{0 . 9 0 3}$ \\
HE & & & & \\
H1 & 0.87 & 33.15 & & \\
H2 & 0.92 & 36.34 & & $\mathbf{0 . 8 2 6}$ \\
H3 & 0.81 & 29.92 & & \\
SC & & & $\mathbf{0 . 6 1 4}$ & \\
S1 & 0.75 & 25.42 & & \\
S2 & 0.82 & 28.54 & & \\
S3 & 0.77 & 26.23 & & \\
\hline
\end{tabular}

\begin{tabular}{rcccc} 
Table 8 & \multicolumn{2}{c}{ CFA for All X Model } \\
\hline & $\begin{array}{c}\text { Completely } \\
\text { Standardized } \\
\text { Loading }\end{array}$ & $\begin{array}{c}\text { Average } \\
\text { Variance } \\
\text { t-statistics }\end{array}$ & $\begin{array}{c}\text { Composite } \\
\text { Eeliability }\end{array}$ \\
\hline Cl & & & $\mathbf{0 . 7 5 1}$ & $\mathbf{0 . 9 0 0}$ \\
C1 & 0.91 & 35.23 & & \\
C2 & 0.86 & 32.37 & & \\
C3 & 0.83 & 30.49 & $\mathbf{0 . 6 2 3}$ & $\mathbf{0 . 8 6 8}$ \\
ATT & & & & \\
A1 & 0.73 & 25.29 & & \\
A2 & 0.74 & 25.54 & & \\
A3 & 0.81 & 29.29 & & \\
A4 & 0.86 & 31.96 & $\mathbf{0 . 7 5 0 2}$ \\
SAT & & & & \\
T2 & 0.80 & 29.11 & & \\
T3 & 0.91 & 35.13 & & \\
T4 & 0.90 & 34.48 & $\mathbf{0 . 8 7 2}$ \\
PAU & & & $\mathbf{0 . 6 3 2}$ & \\
D1 & 0.77 & 27.16 & & \\
D2 & 0.84 & 30.55 & & \\
D3 & 0.86 & 31.74 & & \\
D4 & 0.70 & 23.68 & & \\
\hline
\end{tabular}

Composite reliability is a way to measure internal consistency of constructs. The recommended composite reliability value for an adequate model is 0.7 or higher per construct (Barclay et al. 1995; Chin, 1998; Fornell \& Larcker, 1981; Komiak \& Benbasat 2006). All composite reliability scores for all constructs were higher than 0.826 .

The results of the discriminant validity assessments are shown in Table 9 and Table 10. The tables show that the square root of AVE for all constructs is greater than the correlations among the constructs where the square root of the AVEs is found on the diagonal line (Chin, 1998; Fornell \& Larcker 1981; Gefen \& Straub 2000; Komiak \& Benbasat 2006). Thus, adequate discriminant validity between constructs exists.

Table 9 Discriminant Validity for All X Model

\begin{tabular}{lccccc}
\hline \multicolumn{5}{c}{ Composite Reliabil- } & \\
ity & & AVE & PU & HE & SC \\
\hline PU & 0.894 & 0.741 & $\mathbf{0 . 8 6 1}$ & & \\
HE & 0.903 & 0.756 & 0.490 & $\mathbf{0 . 8 6 9}$ & \\
SC & 0.826 & 0.614 & 0.470 & 0.590 & $\mathbf{0 . 7 8 4}$ \\
\hline (Square root of AVE is on the diagonal) & & &
\end{tabular}


Table 10 Discriminant Validity for All Y Model

\begin{tabular}{|c|c|c|c|c|c|c|}
\hline & $\begin{array}{l}\text { Composite Reli- } \\
\text { ability }\end{array}$ & AVE & $\mathrm{Cl}$ & SAT & ATT & PAU \\
\hline $\mathrm{Cl}$ & 0.900 & 0.751 & 0.866 & & & \\
\hline SAT & 0.868 & 0.623 & 0.530 & 0.789 & & \\
\hline ATT & 0.902 & 0.755 & 0.500 & 0.480 & 0.869 & \\
\hline PAU & 0.872 & 0.632 & 0.430 & 0.320 & 0.360 & 0.795 \\
\hline
\end{tabular}

\section{Full Structural Model - SNAPUM}

With the measurement models completed, a full structural model was run using the LISREL structural equation modeling tool, including both endogenous and exogenous variables. The path diagram of the full model run is shown in Figure 2.

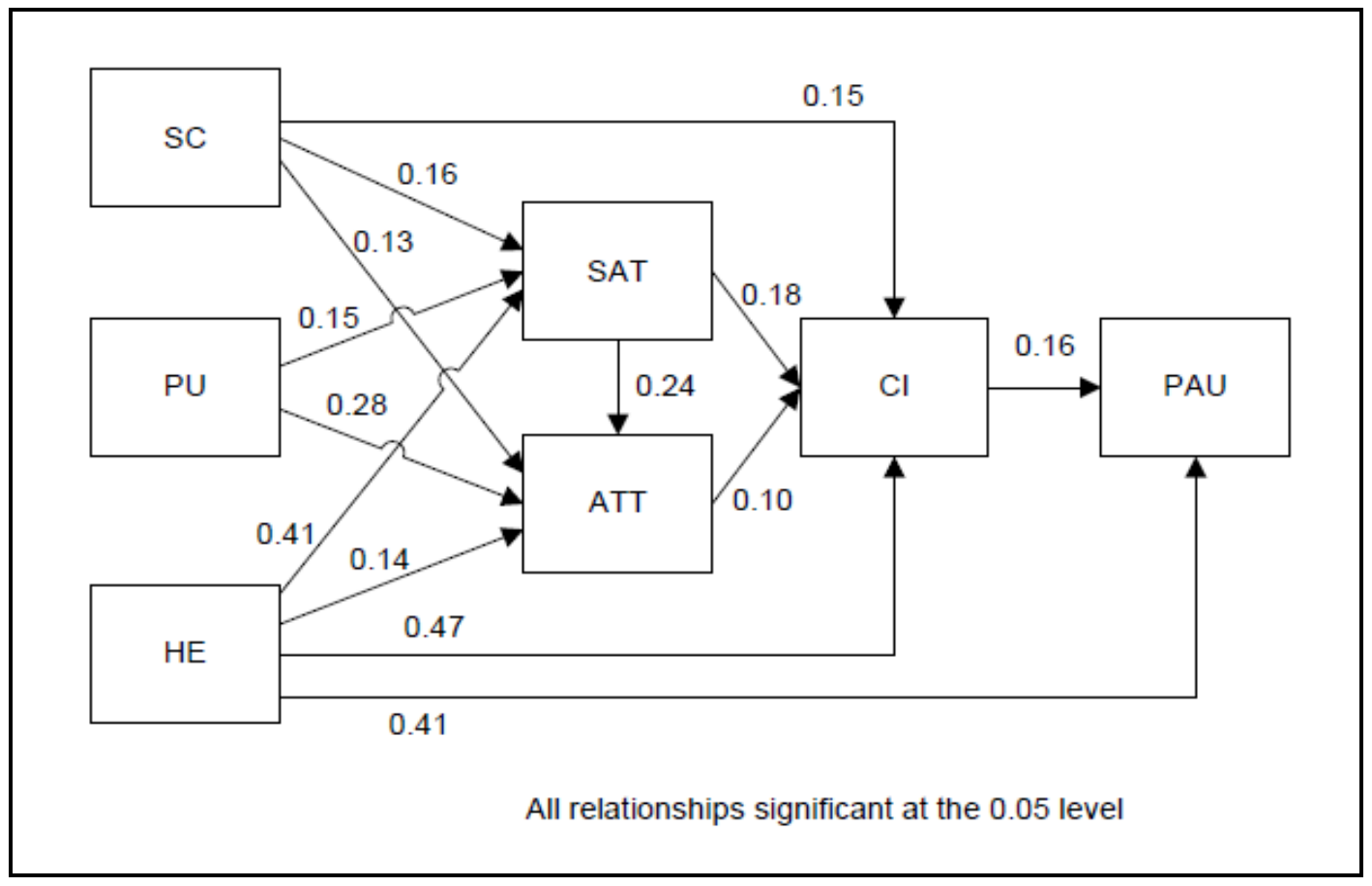

Figure 2: SNAPUM Model with LISREL Standardized Path Co-Efficients

The fit indices and other relevant statistics regarding the model fit were examined. Table 11 shows the fit indices of the full structural model run as well as the recommended statistical values for good model fit established by published and cited works. Additionally, the research model was compared with additional models similar to the TAM and UTAUT models for model fit. Overall, the research model is a better fit for the data than the alternate models resembling UTAUT and TAM. 
Table 11 Comparative Fit Indices for Full SNAPUM Structural Model

\begin{tabular}{cccccc}
\hline & SNAPUM & TAM $^{*}$ & UTAUT* & Recommended & Source \\
\hline X $^{2} / \mathrm{df}$ & $\mathbf{2 . 9 0 4}$ & 3.941 & 3.554 & $\leq 3.0$ & Simon and Paper 2007 \\
RMSEA & $\mathbf{0 . 0 4 4}$ & 0.055 & 0.051 & $\leq 0.1$ & Byrne 2001 \\
GFI & 0.95 & 0.95 & $\mathbf{0 . 9 6}$ & $\geq .90$ & Gefen et. al 2000 \\
AGFI & 0.93 & 0.93 & $\mathbf{0 . 9 4}$ & $\geq .80$ & Gefen et. al 2000 \\
CFI & $\mathbf{0 . 9 9}$ & 0.98 & 0.96 & $\geq .90$ & Simon and Paper 2007 \\
NFI & $\mathbf{0 . 9 8}$ & 0.97 & 0.98 & $\geq .90$ & Gefen et. al 2000 \\
NNFI & $\mathbf{0 . 9 9}$ & 0.98 & 0.98 & $\geq .90$ & Simon and Paper 2007 \\
PGFI & $\mathbf{0 . 7 3}$ & 0.69 & 0.69 & $\geq .50$ & Chang et. al, (n.d.) \\
IFI & $\mathbf{0 . 9 9}$ & 0.98 & 0.98 & $\geq .90$ & Bollen, 1990 \\
\hline $\begin{array}{l}\text { *Note: For consistency in comparison and in line with our research objectives, continuance intention and post-adoptive use were used } \\
\text { instead of the initial acceptance variables of intention and usage in the TAM and UTAUT models. Also, moderators present in UTAUT } \\
\text { were not included for the same reasons they are not part of the research model as described earlier. }\end{array}$
\end{tabular}

The chi-square value for the full model is 615.66 with 211 degrees of freedom. In many circumstances, the chi-square value divided by the degrees of freedom can serve as a fit indicator, with values less than or equal to 3 indicating adequate model fit (Simon \& Paper, 2007). The chisquare divided by the degrees of freedom is 2.904 in the full model, below the recommended threshold of 3 , indicating adequate fit. Overall the fit indicators indicate a good model fit.

\section{Results}

All paths were hypothesized to yield positive associations. All hypothesized relationship paths reflected positive and significant associations between latent constructs at an alpha of 0.05 . The results of the relationships are detailed in Table 12.

Table 12 Hypothesis Support

\begin{tabular}{cccccc}
\hline Hyp. \# & Relationship & T-statistic & p-value & $\beta$ & Supported? \\
\hline H1 & CI -> PAU & 3.12 & 0.00103 & 0.18 & Yes \\
H2 & SAT -> Cl & 4.96 & 0.00000 & 0.18 & Yes \\
H3 & SAT -> ATT & 5.80 & 0.00000 & 0.19 & Yes \\
H4 & ATT -> Cl & 2.95 & 0.00177 & 0.12 & Yes \\
H5 & SC -> Cl & 3.97 & 0.00005 & 0.15 & Yes \\
H6 & SC -> SAT & 3.68 & 0.00015 & 0.17 & Yes \\
H7 & SC -> ATT & 2.98 & 0.00161 & 0.10 & Yes \\
H8 & PU -> SAT & 4.15 & 0.00002 & 0.13 & Yes \\
H9 & PU -> ATT & 7.44 & 0.00000 & 0.19 & Yes \\
H10 & HE -> SAT & 9.52 & 0.00000 & 0.41 & Yes \\
H11 & HE -> ATT & 3.12 & 0.00103 & 0.11 & Yes \\
H12 & HE -> Cl & 11.99 & 0.00000 & 0.45 & Yes \\
H13 & HE -> PAU & 8.20 & 0.00000 & 0.46 & Yes \\
\hline
\end{tabular}




\section{Discussion}

This study proposed and empirically tested a model of factors influencing the post-adoptive use of Facebook. Thirteen hypotheses were proposed, and all were supported. The data show that continuance intention and hedonic enjoyment are directly and significantly related to postadoptive use. This confirms that an individual's intention to use an SNA, along with the pleasure from using it, significantly impact the duration, intensity, and frequency of use. Four factors influence continuance intention: social capital, satisfaction, attitude, and hedonic enjoyment. In terms of social capital, the results show that SNA users believe that the benefits they realize through their SNA relationships are significant. In addition, satisfaction, attitude, and hedonic enjoyment influence their intention to continue to use it. Furthermore, perceived usefulness is an antecedent to both satisfaction and enjoyment. These findings further substantiate Cohen's (2009) contention that psychological factors have a bearing on what information clients perceive, how they assess that information, and, ultimately, what information they decide to act upon..

Facebook, like other informing systems, consists of an informing environment, a delivery system, and a task completion system. The informing environment which services the informers is made up of the Facebook interface which is easy to use (technically, just the parts that allow for content sharing). The delivery system bestows the ability to share information through both manual and automated means, distribute the application throughout the world, as well as make it available on a wide range of Internet-connected devices. The task completion system allows the clients to act upon the information received. We note, however, that in Facebook there is not a distinct divide between informers and clients. For example, an informer may share a news article or image with their friends. If a friend clicks the 'Like' icon relating to that post, are they a client or an informer? In one sense, they have simply acknowledged the receipt of that information, yet in another sense they have informed the original poster that their offering was appreciated. A Facebook poster therefore has the ability to assess the impact of his or her information by how many "likes" it receives (a lack of people liking their post may mean people haven't seen it, or that they simply do not find it worthwhile - there is no "dislike" button).

Thus, the roles of informer and client are blurry in Facebook. The SNAPUM model illustrates that social capital, hedonic enjoyment, and perceived usefulness all have a role in why people continue to use Facebook, but these motivational factors must necessarily be different for each person and for each role that person values. It is likely that not every Facebook user maintains a balance of roles in the manner in which they use the system. We do not know, for example, which factor is most important for those who primarily value Facebook as a source of information and, therefore, whose preferred role is that of the client. Usefulness may be the dominant factor for this type of person, but that supposes the social benefit of knowing the information is less important than the practical aspect of knowing it. Conversely, those that post a lot and thus primarily act as informers could be doing so out of a sense of self-worth they experience through informing others, which is social capital. This does not preclude, however, those same posters appreciating the usefulness of a system that allows them to communicate the same thing to many friends at once in an interactive format. There is also the question of what is truly enjoyable (hedonic) to a specific Facebook user, whether it is informing others, reading the statuses of others, or a balance of both.

\section{Limitations}

As is common with all sample surveys, this study is subject to sampling error (Braverman, 1996). This study sampled university students in a class-based setting that resulted in the respondents being from a narrow age range and from primarily business-oriented majors. The population was further limited to being from primarily a North American English-speaking culture, and the sur- 
veys were all administered in English only. This population is not representative of all SNA users, and caution should be taken when generalizing the results to any other population.

Common methods bias (CMB) may also exist, due to the same method being used to collect data from the population. Common methods bias was assessed through three methods: Harman's onefactor test (Podsakoff \& Organ, 1986), confirmatory factor analysis (Bock, Sabherwal, \& Qian 2008), and the common method factor test (Podsakoff, MacKenzie, Lee, \& Podsakoff, 2003). In Harman's one-factor test, all the measuring items were entered together into a principal components factor analysis and the results yielded 10 factors, with the first factor explaining $36.1 \%$ of the variance and supports the contention that common method bias was not an issue (Podsakoff \& Organ, 1986). No general factor was apparent in the unrotated factor solution. In the second test, confirmatory factor analysis was performed in LISREL including all measuring items, with each latent construct linked to the items measuring it. The square root of the average variance extracted for each construct was found to exceed the correlation with other constructs. The final test was the common method factor test performed in LISREL. In this test, a single latent variable was added to the model, and all measurement items mapped as indicators of the added latent variable. The model with the common method factor would not converge without a reduction of paths, indicating that it was not a better fit than the full structural model and that common method bias was not an issue. The results of all three tests suggest that common methods bias was not a significant problem in this study.

\section{Future Research}

In the spirit of the philosophy of informing science (Cohen 2009), the results of this study should have transdisciplinary implications for future research, especially in the fields of information systems, communication, and the behavioral sciences.

Future research building on this study should include a continuous refinement process by which the instrument is made more parsimonious through fewer scale items, which contributes to the goal of making it more effective in measuring the constructs it purports to measure. During the study process, several of the initial measurement items that performed poorly were dropped to facilitate parsimony and more reliable measures. Applying the survey instrument to users of other SNAs beside Facebook may result in a further reduction in measurement items.

Another application of this study that will further knowledge on SNAs is to administer the survey to other groups of respondents. There is a demographic of SNA users that are older persons who use SNAs to communicate with family, and many people of college age who are working in industry also use SNAs while at work. Testing the survey's predictive power on different groups of respondents may reveal whether or not there are effective moderators that should be added, or whether there are missing constructs that might offer more explanatory power over the existing instrument. Besides age, other factors of interest include location (region, country, etc.), culture, organizational environment, gender, level of income, and educational background.

The post-adoptive usage construct was designed to reflect a greater degree of usage (i.e. "deep usage") than previous studies have used. Yet it is still in the middle of the Burton-Jones and Straub (2006) usage continuum. Developing an even richer measure of system usage would enhance the accuracy of future versions of this model.

Another opportunity to further knowledge would be to identify and classify the roles in SNA usage from the perspective of the client/informer. As previously mentioned, it is simplistic to assume that those posting content on Facebook are always the informers and those reading the content are always the clients. Facebook users have all seen posts designed to solicit other posts, stimulate reaction or steer conversation toward something the poster wants to participate in, suggesting that these roles are not as clear-cut as might be supposed. 
Models always simplify and reduce the relationships they are built to emulate. The motivation to utilize a SNA is likely influenced by many factors that are not represented in our model. It is intriguing to imagine what unmeasured factors might result in significant change in SNA usage behavior. For example, are there instances where Facebook users move to a new stage in life (i.e., get married, graduate and look for a job, etc.) and change their usage behavior due to their new situation? Or for that matter, what about users from different cultures with less freedom of expression? Do these factors influence the users of SNAs, either toward a different level of use, or even a cessation of use? These are all good questions for future studies.

\section{Conclusion}

This study began with the goal of addressing the following research question: What factors contribute to users continuing to use Facebook after adopting it? To begin to answer this question, we first reviewed and synthesized prior adoption and post-adoptive use studies and examined these studies' applicability to a new context, that of social networking applications. Drawing upon information systems, marketing, psychology, and communications literatures, this research proposed a theoretical model for predicting social networking application post-adoptive use (SNAPUM), and tested it through a sample survey of Facebook users. The results show the transdisciplinary SNAPUM model is a better fit for SNA data than the TAM and UTAUT model structures which are well-tested models for studying information technology use. The thirteen hypotheses proposed by this model were all supported. The results show that the user's satisfaction with their SNA, their attitude toward their SNA, the user's hedonic enjoyment of the SNA, and social capital were significantly related to the user's intention to continue using their SNA.

Social capital is a critical factor in our model. We believe the importance of social capital in technology is signaling a paradigm shift (e.g., Fichman, 2004) in the informing environment, and in how people interact with each other, and is a key driver for both online and offline relationships. Social networking applications, and social media, in general, are pervasive in society and have become a significant part of users' everyday lives. In addition, an increasing number of businesses are tying social media into their customer portals as well as using these types of tools internally for collaboration. It is becoming clear that social capital derived from these relationships will play a significant part in technological innovations and informing science for the foreseeable future. Most textbook definitions of information systems include "people" as an important component. In the past, the person involved in the operation of an information system could usually be counted on to use the system the way it was intended and did not expect much more than usability and appropriateness for the task. We are now becoming entrenched in an era in which social media interactions are the norm. People are growing up accustomed to being able to follow their friends', co-workers', and families' lives in a semi-transparent way that had not been imagined when information systems were first defined. We see the inclusion of social capital in technology as more than just a growing trend. Social capital should be considered for inclusion in many of our future transdisciplinary research models. The ubiquity of mobile devices and accessibility to a myriad of innovative connection and communication applications have enabled users to interact socially in tandem with their other activities, thus making traditionally non-social activities potentially social. We expect a key contribution of our research to be an increase the use of social capital in future Informing Science studies.

Another important contribution of our work is the development of an instrument (see Appendix) that was tested for validity and reliability through the process of this research. The items detailed in the instrument can be used immediately to study similar phenomena or adapted according to the research needs of investigators of related phenomena. Over the years, system use has been the dependent variable for a continuous stream of technology adoption studies. However, many have deemed its measurement as inadequate because the lack of richness (e.g., Benbasat and Barki 
2007, Straub and Burton-Jones 2007). In this study we further develop the system usage construct used in Venkatesh et al. (2008) by adding items designed to measure the breadth of usage in addition to frequency, duration and intensity, thus notably advancing the measurement of usage toward the rich category. This is especially important to Information Systems literature because usage is a key dependent variable that often reflects the success of an information system.

This study's contributions to industry practice include the establishment of the full structural model, which can serve as a first step toward understanding the relationships between the factors that influence post-adoptive usage of SNAs. This may be important for organizations that are pursuing commercial utilization of online social networking with their customers and within their organization. Our findings that user attitude and satisfaction are important predictors of usage intention suggest that organizational managers should periodically survey users with the purpose of improving the probability of continued future usage.

Organizations that desire to understand things such as why their employees gravitate toward using SNAs at work, or how much a factor like social capital might influence the usefulness of a proposed new system, should find the results of this study useful. A potential use of this study in an organizational setting might be to help develop an understanding of the degree to which the various factors are positively associated with other factors and using that understanding to increase usage of internal systems. For example, the model reveals that social capital has an influential relationship with satisfaction and continuance intention and that hedonic enjoyment has a very strong relationship with continuance intention, satisfaction, and post-adoptive use. Organizations desiring to utilize social networking applications to increase collaboration or a sense of community among their employees should recognize from the results of this study the importance of cultivating particular aspects of social capital and overall enjoyment in order to increase the level of satisfaction experienced by the users of the system.

In summary, this study set out to provide a predictive model for post-adoption of social networking applications. Through the lens of a transdisciplanary approach, a predictive model was formulated and tested and was found to have predictive power among SNA users. This study demonstrates that the critical factors of social capital, hedonic enjoyment, perceived usefulness, satisfaction, and attitude all influence a user's intention to continue using a social networking application, which in turn influences the user's post-adoptive use of SNAs. These support Cohen's (2009) assertion that psychological issues influence how clients notice, evaluate, and act on information provided.

\section{References}

Acquisti, A., and Gross, R. (2006). Imagined communities: Awareness, information sharing, and privacy on the Facebook. Lecture Notes in Computer Science, (4258), 36-58.

Agarwal, S., \& Mital, M. (2009). An exploratory study of Indian university students' use of social networking websites: implications for the workplace. Business Communication Quarterly, 72(1), 105-110.

Ahuja, M. K., \& Thatcher, J. B. (2005). Moving beyond intentions and toward the theory of trying: Effects of work environment and gender on post-adoption information technology use. MIS Quarterly, 29(3), 427-459.

Al-Natour, S., \& Benbasat, I. (2009). The adoption and use of IT artifacts: A new interaction-centric model for the study of user-artifact relationships. Journal of the Association for Information Systems, 10(9), 661-685.

Arthur, D., Sherman, C., Appel, D., \& Moore, L. (2006). Why young consumers adopt interactive technologies. Young Consumers, 7(3), 33.

Bailey, D.S., and Zanders, E.D. (2008). Drug discovery in the era of Facebook--new tools for scientific networking. Drug Discovery Today, 13(19-20), 863-868. 
Baker-Eveleth, L., Eveleth, D.M., and Sarker, S. (2005). An emerging on-line "Third Place" for information systems (IS) students: Some preliminary observations. Journal of Information Systems Education, 16(4), 465-475.

Barclay, D., Thompson, R., \& Higgins, C. (1995). The partial least squares (PLS) approach to causal modeling: Personal computer adoption and use in illustration. Technology Studies, 2(2), 285-309.

Bearden, W. O., \& Teel, J. E. (1983). Selected determinants of consumer satisfaction and complaint reports. Journal of Marketing Research, 20(1), 21-28.

Beatty, R. C., Shim, J. P., \& Jones, M. C. (2001). Factors influencing corporate website adoption: A time based assessment. Information and Management, 38, 337-354.

Beer, D. (2008). Social network(ing) sites... revisiting the story so far: A response to danah boyd \& Nicole Ellison. Journal of Computer-Mediated Communication, 13(2), 516-529.

Benbasat, I., \& Barki, H. (2007). Quo vadis, TAM? Journal of the Association for Information Systems, $8(4), 212-218$.

Bhattacherjee, A. (2001). Understanding information systems continuance: An expectation-confirmation model. MIS Quarterly, 25(3), 351-370.

Bhattacherjee, A., \& Premkumar, G. (2004). Understanding changes in belief and attitude toward information technology usage: A theoretical model and longitudinal test. MIS Quarterly, 28(2), 229-254.

Bock, G., Sabherwal, R. \& Qian, Z. (2008). The effect of social context on the success of knowledge repository systems. IEEE Transactions on Engineering Management, 55(4), 536-551.

Bolar, K.P. (2009). Motives behind the use of social networking sites: An empirical study. ICFAI Journal of Management Research, 8(1), 75-84.

Bouman, W., Hoogenboom, T., Jansen, R., Schoondorp, M., de Bruin, B., \& Huizing, A. (2007). The realm of sociality: Notes on the design of social software. Sprouts Working Papers on Information Systems, University of Amsterdam, Netherlands. Retrieved on July 15, 2012 from http://sprouts.aisnet.org/8-1/

Boyd, D. M. (2008). Taken out of context: American teen sociality in networked publics. Dissertation University of California, Berkeley.

Boyd, D.M., and Ellison, N.B. "Social Network Sites: Definition, History, and Scholarship," Journal of Computer-Mediated Communication (13:1) 2007, pp 210-230.

Braverman, M.T. (1996). Sources of survey error: Implications for evaluation studies. In M.T. Braverman \& J.K. Slater (Eds.), Advances in Survey Research (pp. 17-28). San Francisco, CA: Jossey-Bass.

Brown, J., Broderick, A.J., and Lee, N. (2007). Word of mouth communication within online communities: Conceptualizing the online social network. Journal of Interactive Marketing, 21(3) 2-20.

Bruque, S., Moyano, J., and Eisenberg, J. (2008). Individual adaptation to IT-induced change: The role of social networks. Journal of Management Information Systems, 25(3), 177-206.

Bumgarner, B.A. (2007). You have been poked: Exploring the uses and gratifications of Facebook among emerging adults. First Monday, 12(11), n.p.

Burton-Jones, A., \& Straub, D. (2006). Reconceptualizing system usage: An approach and empirical test. Information Systems Research, 17(3), 228-246.

Cardon, P.W. (2009). Online social networks. Business Communication Quarterly, 72(1), 96-97.

Chin, W. W. (1998). Issues and opinion on structural equation modeling. MIS Quarterly, 22(1), vii-xvi.

Chiu, C.-M., Hsu, M.-H., \& Wang, E. T. G. (2006). Understanding knowledge sharing in virtual communities: An integration of social capital and social cognitive theories. Decision Support Systems, 42(3), 1872-1888. 
Cohen, E. B. (2009). A philosophy of informing science. Informing Science: the International Journal of an Emerging Transdiscipline, 12, 1-15. Retrieved on July 15, 2012 from http://www.inform.nu/Articles/Vol12/ISJv12p001-015Cohen399.pdf

Connell, R.S. (2009). Academic libraries, Facebook and MySpace, and student outreach: A survey of student opinion. Libraries and the Academy, 9(1), 12.

Corbett, P. (2009). 2009 Facebook demographics and statistics report: 276\% growth in 35-54 year old users. Istrategylabs.com. Retrieved on July 15, 2012 from http://istrategylabs.com/2009/01/2009facebook-demographics-and-statistics-report-276-growth-in-35-54-year-old-users/.

Davis, F. D. (1986). A technology acceptance model for empirically testing new end-user information systems : theory and results. Thesis - Massachusetts Institute of Technology, Sloan School of Management.

Davis, F. D., Bagozzi, R. P., \& Warshaw, P. R. (1989). User acceptance of computer technology: A comparison of two theoretical models. Management Science, 35(8), 982-1003.

Davis, F. D., \& Venkatesh, V. (2004). Toward preprototype user acceptance testing of new information systems: Implications for software project management. IEEE Transactions on Engineering Management, 51(1), 31-46.

DiMicco, J. M., \& Millen, D. R. (2007). Identity management: Multiple presentations of self in Facebook. Proceedings of the 2007 International ACM Conference on Supporting Group Work, ACM, Sanibel Island, Florida, USA.

DiMicco, J. M., Millen, D. R., Geyer, W., Dugan, C., Brownholtz, B. \& Muller, M. (2008). Motivations for social networking at work. Proceedings of the 2008 Computer Supported Cooperative Work Conference, ACM, San Diego, California, USA, 711-720.

Donath, J., \& Boyd, D. (2004). Public displays of connection. BT Technology Journal, 22(4), 71-82.

Drentea, P., \& Moren-Cross, J. L. (2005). Social capital and social support on the web: The case of an internet mother site. Sociology of Health \& Illness, 27(7), 920-943.

Dwyer, C., Hiltz, S. R. \& Passerini, K. (2007). Trust and privacy concern within social networking sites: A comparison of Facebook and MySpace. Proceedings of the Thirteenth America's Conference on Information Systems, Keystone, Colorado, USA.

Dwyer, C., Hiltz, S. R. \& Widmeyer, G. (2008). Understanding development and usage of social networking sites: The social software performance model. Proceedings of the $41^{s t}$ Hawaii International Conference on System Sciences.

Ellison, N. B. (2007). Facebook use on campus: A social capital perspective on social network sites. Presentation at the ECAR Symposium 2007, Boca Raton, Florida.

Ellison, N., Steinfield, C., and Lampe, C. (2006). Spatially bounded online social networks and social capital: The role of Facebook. Proceedings of the Annual Conference of the International Communication Association, Dresden, Germany, 2006.

Ellison, N. B., Steinfield, C., \& Lampe, C. (2007). The benefits of Facebook friends: Social capital and college students' use of online social network sites. Journal of Computer-Mediated Communication, $12(4), 1143-1168$.

Fichman, R. G. (2004). Going beyond the dominant paradigm for information technology innovation research: Emerging concepts and methods. Journal of the AIS, 5(8), 314-355.

Fogel, J., \& Nehmad, E. (2009). Internet social network communities: Risk taking, trust, and privacy concerns. Computers in Human Behavior, (25:1), 153-160.

Fornell, C., \& Larcker, D. F. (1981). Evaluating structural equation models with unobservable variables and measurement error. Journal of Marketing Research, 18(1), 39-50. 
Gefen, D., Karahanna, E., \& Straub, D. W. (2003). Trust and TAM in online shopping: An integrated model. MIS Quarterly, 27(1), 51-90.

Gefen, D., \& Straub, D. W. (2000). The relative importance of perceived ease of use in IS adoption: A study of e-commerce adoption. Journal of the Association for Information Systems, 1(8), 1-28.

Gill, T. G., \& Cohen, E. B. (2008). Research themes in complex informing. Informing Science: the International Journal of an Emerging Transdiscipline, 11, 147-165. Retrieved on July 15, 2012 from http://www.inform.nu/Articles/Vol11/ISJv11p147-164GillIntro.pdf

Granovetter, M. S. (1982). The strength of weak ties: A network theory revisited. In P. V. Marsden \& N. Lin (Eds.), Social structure and network analysis (pp. 105-130). Beverly Hills, CA: Sage.

Hair, J. F., Jr., Black, W. C., Babin, B. J., Anderson, R. E., \& Tatham, R. L. (2006). Multivariate Data Analysis (6th ed.). Upper Saddle River, NJ: Pearson Prentice Hall.

Hardawar, D. (2010). Facebook ousts Google as most popular U.S. site. VentureBeat, March 15, 2010, retrieved on July 15, 2012 from http://venturebeat.com/2010/03/15/facebook-ousts-google-as-mostpopular-u-s-site/.

Hargittai, E. (2008). Whose space? Differences among users and non-users of social network sites. Journal of Computer-Mediated Communication, 13(1), 276-297.

Hewitt, C. (1986). Offices are open systems. ACM Transactions on Office Information Systems, 4(3), 271287.

Hewitt, A., \& Forte, A. (2006). Crossing boundaries: Identity management and student/faculty relationships on the Facebook. Proceedings of the 2006 Computer Supported Cooperative Work Conference, ACM, Banff, Alberta, Canada.

Hinduja, S., and Patchin, J.W. (2008). Personal information of adolescents on the Internet: A quantitative content analysis of MySpace. Journal of Adolescence, (31:1), 125-146.

Horowitz, B. T. (2009). How Facebook can boost your well-being. womansday.com. Retrieved on July 15, 2012 from http://www.womansday.com/health-fitness/how-facebook-can-boost-your-well-being64734.

Hsieh, J. P. A., \& Zmud, R. W. (2006). Understanding post-adoptive usage behaviors: A two-dimensional view. DIGIT Workshop, Milwaukee, WI, USA.

Hsu, C. L. \& Lin, J. C. (2008). Acceptance of blog usage: The roles of technology acceptance, social influence and knowledge sharing motivation. Information and Management, 45, 65-74.

Hu, T. \& Kettinger, W. J. (2008). Why people continue to use social networking services: Developing a comprehensive model. Proceedings of the twenty-ninth International Conference on Information Systems, Paris, France.

Hu, X., Lin, Z., Whinston, A. B. \& Zhang, H. (2004). Hope or hype: On the viability of escrow services as trusted third parties in online auction environments. Information Systems Research, 15(3), 236-249.

Huber, G. (1982). Organizational information systems: Determinants of their performance and behavior. Management Science, 28(2), 138-155.

Hunt, H. K. (1977). CS/D - Overview and future research directions. In H. K. Hunt (Ed.), Conceptualizion and measurement of consumer satisfaction and dissatisfaction (pp. 77-103). Cambridge, MA: Marketing Science Institute.

Inkpen, A. C., \& Tsang, E. W. K. (2005). Social capital, networks, and knowledge transfer. Academy of Management Review, 30(1), 146-165.

Jasperson, J. S., Carter, P. E., \& Zmud, R. W. (2005). A comprehensive conceptualization of the postadoptive behaviors associated with IT-enabled work systems. MIS Quarterly, 29(3), 525-557.

Jessup, L. \& Valacich, J. (2006). Information systems today: Why IS matters. New Jersey: Prentice Hall. 
Joinson, A. N. (2008). Looking at, looking up or keeping up with people? Motives and use of Facebook. Proceedings of the twenty-sixth annual SIGCHI Conference on Human Factors in Computing Systems.

Jones, M. C. \& Beatty, R. C. (2001). User satisfaction with EDI: An empirical investigation. Information Resources Management Journal, 14(2), 17-26.

Karahanna, E., Straub, D. W., \& Chervany, N. L. (1999). Information technology adoption across time: A cross-sectional comparison of pre-adoption and post-adoption beliefs. MIS Quarterly, 23(2), 183-213.

Kerlinger, F. N., \& Lee, H. B. (2000). Foundations of behavioral research (4th ed.). Orlando, FL: Harcourt-Brace.

Kim, S .S., Malhotra, N. K., \& Narasimhan, S. (2005). Two competing perspectives on automatic use: A theoretical and empirical comparison. Information Systems Research, 16(4), 418-432.

Kim, S.S., \& Son, J.-Y. (2009). Out of dedication or constraint? A dual model of post-adoption phenomena and its empirical test in the context of online services. MIS Quarterly, 33(1), 49-70.

Komiak, S. Y. X., \& Benbasat, I. (2006). The effects of personalization and familiarity on trust and adoption of recommendation agents. MIS Quarterly, 30(4), 941-960.

Kuo, J. P., Lai, C. P., \& Wang, C. (2008). Social participation and life satisfaction: From youth's social capital perspective. Journal of American Academy of Business, Cambridge, 12(2), 237-242.

Kwon, H. S. \& Chidambaram, L. (2000). A test of the Technology Acceptance Model: The case of cellular telephone adoption. Proceedings of the $33^{\text {rd }}$ Hawaii International Conference on System Sciences.

Lampe, C., Ellison, N. \& Steinfield, C. (2006). A Face(book) in the crowd: Social searching vs. social browsing. Proceedings of the Computer Supported Cooperative Work Conference 2006, Banff, Alberta, Canada, 167-170.

Lampe, C., Ellison, N. \& Steinfield, C. (2008). Changes in use and perception of Facebook. Proceedings of the Computer Supported Cooperative Work Conference 2008, San Diego, California, 721-730.

Lee, L. T-S.L., \& Sukoco, B.M. (2007). The effects of entrepreneurial orientation and knowledge management capability on organizational effectiveness in Taiwan: The moderating role of social capital. International Journal of Management, 24(3), 549-572.

Lee, G., \& Xia, W. (2010). Toward agile: An integrated analysis of quantitative and qualitative field data on software development agility. MIS Quarterly, 34(1), 87-114.

Lenhart, A. (2009). Pew Internet project data memo. Pew Internet \& American Life Project, January 14, 2009 , retrieved on July $15^{\text {th }}, 2012$ from http://www.pewinternet.org/ /media//Files/Reports/2009/PIP_Adult_social_networking_data_memo FINAL.pdf

Lockyer, L., \& Patterson, J. (2008). Integrating social networking technologies in education: A case study of a formal learning environment. Proceedings of the Eighth IEEE International Conference on Advanced Learning Technologies, 2008, 529-533.

Luk, C., Yau, O., Sin, L., Tse, A., Chow, R., \& Lee, J. (2008). The effects of social capital and organizational innovativeness in different institutional contexts. Journal of International Business Studies, 39(4), 589-612.

Magro, M. J., Ryan, S. D., Sharp, J. H., \& Ryan, K. A. (2009). Using social networking for educational and cultural adaptation: An exploratory study. AMCIS 2009 Proceedings.

Malhotra, Y., \& Galletta, D. (1999). Extending the technology acceptance model to account for social influence: Theoretical bases and empirical validation. Proceedings of the $32^{\text {nd }}$ Hawaii International Conference on System Sciences.

Mangalaraj, G., Mahapatra, R., \& Nerur, S. (2009). Acceptance of software process innovations - The case of extreme programming. European Journal of Information Systems, 18(4), 344-354. 
Nahapiet, J., \& Ghoshal, S. (1998). Social capital, intellectual capital, and the organizational advantage. The Academy of Management Review, 23(2), 242-266.

Nysveen, H., Pedersen, P., \& Thorbjornsen, H. (2005). Intentions to use mobile services: Antecedents and cross-service comparisons. Journal of the Academy of Marketing Science, 33(3), 330-346.

Oliver, R. L. (1980). A cognitive model for the antecedents and consequences of satisfaction. Journal of Marketing Research, 17, 460-469.

Oliver, R. L. (1981). Measurement and evaluation of satisfaction processes in retail settings. Journal of Retailing, 57(3), 25-48.

Pasfield-Neofitou, S.E. (2008). Creative applications of social networking for the language learning class. International Journal of Learning, 14(12), 235-239.

Pempek, T. A., Yermolayeva, Y. A., \& Calvert, S. L. (2009). College students' social networking experiences on Facebook. Journal of Applied Developmental Psychology, 30(3), 227-238.

Pfeil, U., Arjan, R., \& Zaphiris, P. (2009). Age differences in online social networking - A study of user profiles and the social capital divide among teenagers and older users in MySpace. Computers in Human Behavior, 25(3), 643-654.

Pikkarainen, T., Pikkarainen, K., Karjaluoto, H., \& Pahnila, S. (2004). Consumer acceptance of online banking: An extension of the technology acceptance model. Internet Research, 14(3), 224-235.

Podsakoff, P. M., MacKenzie, S. B., Lee, J.-Y., \& Podsakoff, N. P. (2003). Common method biases in behavioral research: A critical review of the literature and recommended remedies. Journal of Applied Psychology, 88, 879-903.

Podsakoff, P. M., \& Organ, D. W. (1986). Self reports in organizational research: Problems and prospects. Journal of Management, 12(4), 531-544.

Putnam, R. D. (2000). Bowling alone. New York: Simon \& Schuster.

Rambe, P., \& Ng'ambi, D. (2011). Towards an information sharing pedagogy: A case of using Facebook in a large first year class. Informing Science: The International Journal Of An Emerging Transdiscipline, 14, 62-89. Retrieved from http://www.inform.nu/Articles/Vol14/ISJv14p061-089Rambe579.pdf

Richter, A., and Koch, M. (2008). Functions of social networking services. Proceedings of the Eighth International Conference on the Design of Cooperative Systems, Provence, France.

Robert, L. P., Dennis, A. R., \& Ahuja, M. K. (2008). Social capital and knowledge integration in digitally enabled teams. Information Systems Research, 19(3), 314-334.

Ross, C., Orr, E.S., Sisic, M., Arseneault, J.M., Simmering, M.G., \& Orr, R.R. (2009). Personality and motivations associated with Facebook use. Computers in Human Behavior, 25(2), 578-586.

Ryan, S. D. (2010). Information systems and healthcare XXXVI: Building and maintaining social capitalevidence from the field. Communications of the Association for Information Systems, 27, Article 18.

Ryan, S. D., Harrison, D. A., \& Schkade, L. R. (2002). Information-technology investment decisions: When do costs and benefits in the social subsystem matter? Journal of Management Information Systems, 19(2), 85-127.

Saeed, K. A., \& Abdinnour-Helm, S. (2008). Examining the effects of information system characteristics and perceived usefulness on post adoption usage of information systems. Information \& Management, 45(6), 376-386.

Schonfeld, E. (2008). Top social media sites of 2008 (Facebook still rising). Techcrunch.com. December 31, 2008, retrieved on August 2, 2009 from http://www.techcrunch.com/2008/12/31/top-social-mediasites-of-2008-facebook-still-rising/

Schonfeld, E. (2009). Facebook is now the fourth largest site in the world. Techcrunch.com. August 4, 2009, retrieved on August 30, 2009, from http://www.techcrunch.com/2009/08/12/facebook-grewtwice-as-fast-as-twitter-in-july/ 
Simon, S. J., \& Paper, D. (2007). User acceptance of voice-recognition technology: An empirical extension of the technology acceptance model. Journal of Organizational and End User Computing, 19(1), 2450 .

Sivadas E. \& Baker-Prewitt, J. L. (2000). An examination of the relationship between service quality, customer satisfaction, and store loyalty. International Journal of Retail \& Distribution Management, 28(2), 73-82.

Smith, J. (2009, July 2). Facebook now growing by over 700,000 users a day, and new engagement stats. Inside Facebook. Retrieved on 09/02/2010 from http://www.insidefacebook.com/2009/07/02/facebook-now-growing-by-over-700000-users-a-dayupdated-engagement-stats/

Smith, J. (2010). The Facebook global monitor: Tracking Facebook in global markets. Inside Facebook. Retrieved on 09/02/2010 from http://www.insidefacebook.com/facebook-global-market-monitor/

Snyder, J., Carpenter, D., and Slauson, G.J. (2007). MySpace.com - A social networking site and social contract theory. Information Systems Education Journal, 5(2) 11.

Steinfield, C., Ellison, N. B., \& Lampe, C. (2008). Social capital, self-esteem, and use of online social network sites: A longitudinal analysis. Journal of Applied Developmental Psychology, 29(6), 434-445.

Straub, D. W., Jr., \& Burton-Jones, A. (2007). Veni, vidi, vici: Breaking the TAM logjam. Journal of the Association for Information Systems, 8(4), 224-229.

Subrahmanyam, K., Reich, S. M., Waechter, N., \& Espinoza, G. (2008). Online and offline social networks: Use of social networking sites by emerging adults. Journal of Applied Developmental Psychology, 29(6), 420-433.

Taylor, S., \& Todd, P. A. (1995). Understanding information technology usage: A test of competing models. Information Systems Research, 6(2), 144-176.

Taylor, S. A., \& Hunter, G. (2003). An exploratory investigation into the antecedents of satisfaction, brand attitude, and loyalty within the (B2B) eCRM Industry. Journal of Consumer Satisfaction, Dissatisfaction and Complaining Behavior, 16, 19-35.

Taylor, D. G., \& Strutton, D. (2010). Has e-marketing come of age? Modeling historical influences on postadoption era Internet consumer behaviors. Journal of Business Research, 63(9-10), 950-956.

Tenenhaus, M., Esposito Vinzi, V., Chatelin, Y., \& Lauro, C. (2005). PLS path modeling. Computational Statistics and Data Analysis, 48, 159-205.

Thelwall, M. (2008). Social networks, gender, and friending: An analysis of MySpace member profiles. Journal of the American Society for Information Science and Technology, 59(8), 1321-1330.

van der Heijden, H. (2004). User acceptance of hedonic information systems. MIS Quarterly, 24(4), 695704.

Venkatesh, V., \& Davis, F. D. (2000). A theoretical extension of the technology acceptance model: Four longitudinal field studies. Management Science, 46(2), 186-204.

Venkatesh, V., Morris, M. G., Davis, G. B., \& Davis, F. D. (2003). User acceptance of information technology: Toward a unified view. MIS Quarterly, 27(3), 425-478.

Venkatesh, V., Brown, S. A., Maruping, L. M., \& Bala, H. (2008). Predicting different conceptualizations of system use: The competing roles of behavioral intention, facilitating conditions, and behavioral expectation. MIS Quarterly, 32(3), 483-502.

Vijayasarathy, L. R. (2004). Predicting consumer intentions to use on-line shopping: The case for an augmented technology acceptance model. Information \& Management, 41(6), 747-762.

Wah, C. Y., Menkhoff, T., Loh, B., \& Evers, H. D. (2007). Social capital and knowledge sharing in knowledge-based organizations: An empirical study. International Journal of Knowledge Management, 3(1), $29-46$. 
Wang, S. C., Lii, Y. S., \& Fang, K. T. (2009). Predicting the continuance usage of information systems: A comparison of three alternative models. WSEAS Transactions on Information Science and Applications, 6(2), 301-318.

Warr, W. A. (2008). Social software: Fun and games, or business tools? Journal of Information Science, 34(4), 591-604.

Waterman, A., Schwartz, S., \& Conti, R. (2008). The implications of two conceptions of happiness (hedonic enjoyment and eudaimonia) for the understanding of intrinsic motivation. Journal of Happiness Studies, 9(1), 41-79.

Wu, Y., Ryan, S. D., \& Windsor, J. (2009). Influence of social context and affect on individuals' implementation of information security safeguards. Proceedings of the Thirteenth Annual International Conference on Information Systems, Phoenix 2009.

Yi, M. Y. \& Davis, F. D. (2003). Developing and validating an observational learning model of computersoftware training and skill acquisition. Information Systems Research, 14(2), 146-169.

Zuckerberg, M. (2010). 500 million stories. The Facebook Blog. Posted July 21, 2010, retrieved on 09/02/2010 from http://blog.facebook.com/blog.php?post=409753352130

\section{Appendix}

\section{Measurement Scales and Items}

\section{IMAGE}

(IMG1) People who use my SNA have more prestige than those who do not. (7 point scale, hereafter abbreviated to "7pt"; strongly agree, agree, somewhat agree, neither agree nor disagree, somewhat disagree, disagree, strongly disagree, hereafter abbreviated to "sa/sd") (IMG2) Using my SNA enhances my reputation. (7pt; sa/sd) (IMG3) People who use my SNA are held in higher regard than those who do not. (7pt; sa/sd)

(IMG4) Using my SNA enhances a person's status. (7pt; sa/sd)

\section{SUBJECTIVE NORM (INFLUENCE)}

(SNI1) People who are important to me encourage the use of my SNA. (7pt; sa/sd)

(SNI2) People whom I admire encourage the use of my SNA. (7pt; sa/sd)

(SNI3) People whom I respect encourage the use of my SNA. (7pt; sa/sd)

(SNI4) People who have an influence on me encourage the use of my SNA. (7pt; $\mathrm{sa} / \mathrm{sd}$ )

\section{ATTITUDE}

(ATT1) Fill in the blank in the following sentence: Using my SNA is a(n) idea (7pt.; "extremely foolish" to "extremely wise")

(ATT2) Fill in the blank in the following sentence: Using my SNA yields results. (7pt; "extremely negative" to "extremely positive")

(ATT3) Fill in the blank in the following sentence: Using my SNA is (7pt; "extremely harmful" to "extremely beneficial")

(ATT4) Fill in the blank in the following sentence: Using my SNA is a(n) idea (7pt; "extremely bad" to "extremely good") 


\section{PERCEIVED USEFULNESS}

(PU3) Using my SNA allows me to accomplish the things I use it for quicker than if I did not use a SNA at all. (7pt; sa/sd)

(PU4) Using my SNA allows me to accomplish the things I use it for more effectively than if I didn't use a SNA at all. (7pt; sa/sd)

(PU5) Using my SNA allows me to do things I couldn't do if I did not use a SNA at all. (7pt; sa/sd)

\section{PERCEIVED EASE OF USE}

(PEOU3) I find my SNA easy to use. (7pt; sa/sd)

(PEOU4) Learning to operate my SNA interface is easy for me. (7pt; sa/sd)

\section{HEDONIC ENJOYMENT}

(HE1) My SNA is fun to use (7pt; sa/sd)

(HE2) Using my SNA gives me a sense of enjoyment (7pt; sa/sd)

(HE3) Using my SNA makes me feel good (7pt; sa/sd)

\section{FACILITATING CONDITIONS}

(FC4) I have access to people or online resources that assist me with learning how to operate and use my current SNA. (7pt; sa/sd)

(FC5) I have access to people or online resources that assist me with technological difficulties with my current SNA. (7pt; sa/sd)

(FC6) If I need help using my current SNA, I have access to people or online resources that are effective in assisting me. (7pt; sa/sd)

\section{CONTINUANCE INTENTION}

(CI1) I intend to continue using my current SNA rather than discontinue its use (7pt; sa/sd)

(Cl2) I plan to continue using my current SNA rather than replace it with an alternative non-SNA application, such as e-mail, voice telephony, etc. (7pt; sa/sd)

(Cl4) I would like to continue using my current SNA for the forseeable future. (7pt; sa/sd)

\section{SATISFACTION (How do you feel about your overall experience of using your current SNA?)}

(SAT1) Very satisfied / Very dissatisfied (7pt.)

(SAT2) Very displeased / Very pleased (7pt.)

(SAT3) Very frustrated / Very contented (7pt.)

(SAT4) Absolutely disgusted / Absolutely delighted (7pt.)

\section{SOCIAL CAPITAL (BONDING)}

(SCBO1) There is someone on my SNA I can turn to for advice about making very important decisions. (7pt; sa/sd)

(SCBO2) There are people on my SNA I trust to help solve my problems. (7pt; $\mathrm{sa} / \mathrm{sd}$ ) 
(SCBO4) The people I interact with on my SNA would help me fight an injustice. (7pt; sa/sd)

\section{SOCIAL CAPITAL (BRIDGING)}

(SCBR1) Interacting with people on my SNA makes me curious about places other than where I live. (7pt; sa/sd)

(SCBR2) Interacting with people on my SNA makes me interested in what people who are different than me are thinking. (7pt; sa/sd)

(SCBR3) Interacting with people on my SNA makes me feel like part of a larger community. (7pt; sa/sd)

\section{SOCIAL CAPITAL (MAINTAINED)}

(SCM2) If I needed to, I could ask a high school classmate to do a small favor for me. (7pt; sa/sd)

(SCM3) I would be able to find information about a job or internship from a high school acquaintance. (7pt; sa/sd)

(SCM4) It would be easy to find people to invite to my high school reunion. (7pt; $\mathrm{sa} / \mathrm{sd})$

(SCM5) I'd be able to stay with a high school acquaintance if traveling to a different city. (7pt; sa/sd)

\section{POST-ADOPTIVE USE (duration, frequency, involvement, extent)}

(PAU) On average, how many hours do you use your current SNA each week?

(7pt; "0-1" to "20+")

(PAUFR1) On average during a one-week period, how many times do you access or use your current SNA? (7pt; "0-1" to "50 or more")

(PAUFR2) How often would you say you use your SNA? (7pt; "not very often" to "very often")

(PAUI1) How would you classify the intensity of your involvement experience with your SNA during a typical usage session? (7pt; "very low involvement" to "very high involvement")

(PAUI2) How would you classify the intensity of your immersion into the world of your SNA in a typical usage session? (7pt; "very low immersion" to "very high immersion")

(PAUI3) How would you classify the intensity of your engagement with your SNA in a typical usage session? (7pt; "very low engagement" to "very high engagement")

(PAUE) How many of the available features of your SNA would you say you use? (7pt; "very few features" to "very many features") 


\section{Biographies}

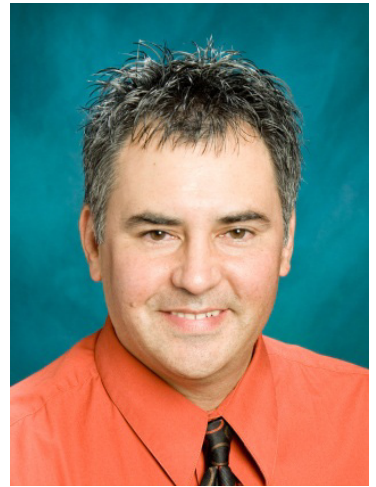

Michael J. Magro is an Assistant Professor of Information Systems and Computing Technology at Shenandoah University in Virginia. He received his Ph.D. in Business Computer Information Systems from the University of North Texas, and has a M.S. in Information Technology from the University of Redlands. Prior to returning to academia, he spent 16 years in the software development and IT solutions industry. His research interests include social networking applications, social media, hedonic information systems, IS development, systems analysis and design, and IS education and teaching. His work has appeared in Informing Science: the International Journal of an Emerging Transdiscipline, Administrative Science, the International Journal of Information and Operations Management Education, the Journal of Information Technology Education, Proceedings of Decision Science Institute and Proceedings of the Americas Conference on Information Systems.

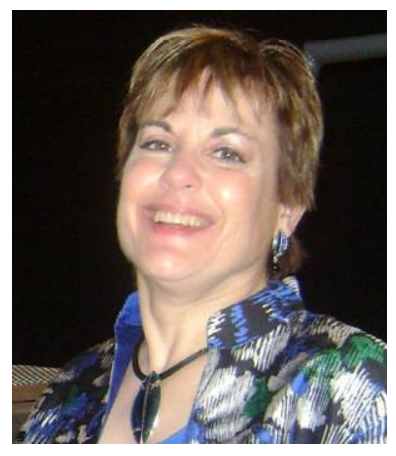

Sherry D. Ryan is an Associate Professor of Information Technology and Decision Sciences at the University of North Texas. She received her Ph.D. in IS from the University of Texas at Arlington and an MBA from the University of Southern California. Prior to returning to academia she worked for IBM, teaching courses and speaking at national conferences. Her research interests include IT human resource issues, knowledge management, and social media. Her work has appeared in journals including Journal of Management Information Systems, Decision Support Systems, and Informing Science: the International Journal of an Emerging Transdiscipline.

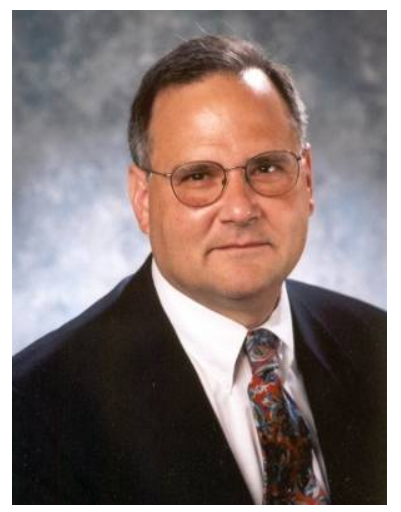

Victor R. Prybutok is a Regents Professor of Decision Sciences in the Information Technology and Decision Sciences Department and Associate Dean of the Toulouse Graduate School at the University of North Texas. He received, from Drexel University, his B.S. with High Honors in 1974, a M.S. in Bio-Mathematics in 1976, a M.S. in Environmental Health in 1980, and a Ph.D. in Environmental Analysis and Applied Statistics in 1984. Dr. Prybutok is an American Society for Quality certified quality engineer, certified quality auditor, certified manager of quality / organizational excellence, and an accredited professional statistician (PSTAT ${ }^{\circledR}$ ) by the American Statistical Association. Dr. Prybutok has authored over 125 journal articles, several book chapters, and more than 130 conference presentations in information systems measurement, quality control, risk assessment, and applied statistics. 